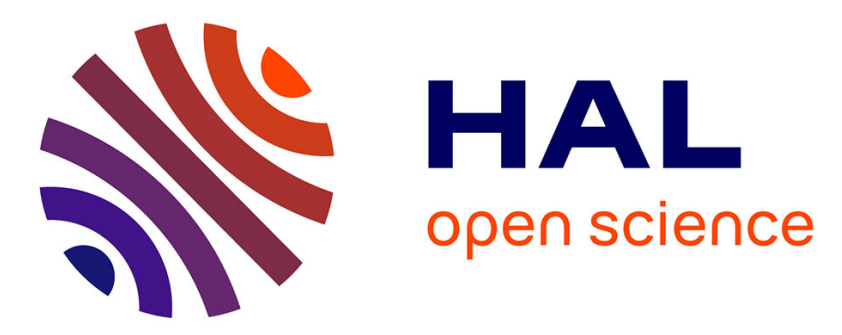

\title{
Isotopic composition of bare soil evaporated water vapor. Part I: RUBIC IV experimental set up and results
}

\author{
Isabelle Braud, P. Biron, Thierry Bariac, Patrick Richard, Laurent Canale,
} J.P. Gaudet, M. Vauclin

\section{- To cite this version:}

Isabelle Braud, P. Biron, Thierry Bariac, Patrick Richard, Laurent Canale, et al.. Isotopic composition of bare soil evaporated water vapor. Part I: RUBIC IV experimental set up and results. Journal of Hydrology, 2009, 369, p. 1 - p. 16. 10.1016/j.jhydrol.2009.01.034 . hal-00455339

\section{HAL Id: hal-00455339 \\ https://hal.science/hal-00455339}

Submitted on 10 Feb 2010

HAL is a multi-disciplinary open access archive for the deposit and dissemination of scientific research documents, whether they are published or not. The documents may come from teaching and research institutions in France or abroad, or from public or private research centers.
L'archive ouverte pluridisciplinaire HAL, est destinée au dépôt et à la diffusion de documents scientifiques de niveau recherche, publiés ou non, émanant des établissements d'enseignement et de recherche français ou étrangers, des laboratoires publics ou privés. 


\section{Isotopic composition of bare soil evaporated water vapor}

\section{Part I: RUBIC IV experimental setup and results}

3

4

5

6

7

8

9

10

11

12

13

14

15

16

17

18

19

20

21

22

23 Corresponding author: Isabelle Braud, Cemagref, UR HHLY, 3bis Quai Chauveau, 69336

Lyon Cedex 9, France, Tel: +33 4722087 78, isabelle.braud@cemagref.fr
(1) Cemagref, UR HHLY, 3bis Quai Chauveau, 69336 Lyon Cedex 9, France

(2) BioEMCo (UMR 7618 CNRS, ENS-Ulm, ENSCP, INRA, AgroParisTech, UPMC) INRA-AgroParisTech, Bâtiment EGER, 78850 Thiverval-Grignon, France

(3) LTHE (UMR 5564 CNRS, INPG, IRD, UJF), BP 53X, 38041 Grenoble, Cédex 9, France 


\section{Summary}

2 Stable water isotopes such as oxygen 18, are natural tracers of water movement within the

3 soil-vegetation-atmosphere continuum. They provide useful information for a better

4 understanding of evaporation and water vapor transport within soils. This paper presents a

5 novel controlled experimental set up. It is dedicated to detailed measurements of the

6 evaporation fluxes from bare soil columns, as well as to the corresponding isotopic

7 composition of the water vapor, under non steady state conditions. The experiment allowed an

8 accurate determination of these quantities. The formulae encountered in the literature were

9 used to estimate the isotopic composition of the evaporated water vapor. None of them was able to correctly reproduce the measured isotopic composition of water. The data were then

11 used to estimate the value of the isotopic composition of the soil liquid water, which should

12 be used to get the right results for the isotopic composition of the evaporated water vapor.

13 Results suggest that, when liquid transfer is dominant within the soil, the isotopic composition of evaporation was controlled by the isotopic composition of the liquid water within very thin soil surface layers. When there is a peak in the isotopic profile, i.e. when water vapor is

16 dominant close to the surface, the isotopic composition of the evaporated water seems to be 17 governed by the isotopic composition of the soil liquid water at the peak. The data were also used to estimate the kinetic fractionation factor. The results suggest that the latter is not constant in time. The values seem to depend on the shape of the isotopic profile. In both cases, the uncertainty on the results is very large. The estimation of the kinetic

21 fractionation factor is studied more in details using the modeling results presented in Part II of 22 a companion paper where the data set is modeled using the SiSPAT_Isotope model.

24 Keywords: Soil water, Water vapor, Soil evaporation, Oxygen 18, Kinetic fractionation factor, RUBIC IV reactor, Laboratory experiment 


\section{Introduction}

3 Evaporation from soils and transpiration by vegetation represent the major rainfall-recycling

4 source over continents (Chahine, 1992, Parlange and Katul, 1992; Costanza et al., 1997;

5 Zangvil et al., 2004). Consequently, a correct assessment of potential impacts of water

6 management practices, land use and/or climate change on water resources relies on an

7 accurate representation of evapotranspiration within atmosphere, hydrological or vegetation

8 models. Soil Vegetation Atmosphere Transfer (SVAT) models represent the complex

9 interactions between the atmosphere, the soil and the biosphere. Most of them provide

separate estimates of soil evaporation, interception by the canopy and transpiration by plants.

11 However, few data (relying mainly on sap flow and micro-lysimeters measurements) are

12 currently available to validate that partition. Stable water isotopes are natural tracers of water movement. They can provide useful information to quantify and understand this partition (Yakir and Sternberg, 2000; Yepez et al., 2003; Williams et al., 2004). The isotopic composition of water within soils is known to be modified under soil evaporation (i.e. Barnes and Allison, 1983), whereas no fractionation of isotopic forms of either oxygen or hydrogen occurs during root extraction (Zimmermann et al., 1967; Walker and Richardson, 1991; Bariac et al., 1994). The isotopic composition of evaporated and transpired water vapor is therefore expected to be different. In the field however, they cannot be measured separately as they are instantaneously mixed with the ambient air water vapor. It is therefore necessary to estimate them from measurements of the isotopic composition of liquid water in soils, leaves and stems (e.g. Yakir and Sternberg, 2000; Yepez et al., 2003; Williams et al., 2004) with formulae established for water bodies or oceans such as the Craig and Gordon (1965) model

24 (Yakir and Sternberg, 2000). Their use for deriving the isotopic composition of soil 
1 evaporation front moves below the surface as the soil dries out. To study the mechanisms

2 controlling the isotopic composition of evaporating soils, we have developed a physically

3 based model, called SiSPAT_Isotope (Braud et al., 2005a) for bare soil, representing the full

4 interactions between the atmosphere, the soil and stable isotope species. The model was

5 evaluated against two sets of laboratory data (Braud et al., 2005b). The data were composed

6 of soil columns which were let evaporating freely in the atmosphere. The results of this first

7 study showed that lots of uncertainty in the modeling and interpretation of stable isotope

8 composition of water in terms of evaporation were related to a lack of control of the

9 experimental conditions, especially of the atmospheric relative humidity and to a lack of

10 knowledge of the kinetic fractionation factor for unsaturated soils. In this paper, we present a

11 novel controlled experiment dedicated to the measurement of the evaporation flux from bare

12 soil columns, as well as its isotopic composition. The experimental set up allowed a precise

13 determination of the atmospheric conditions, of the evaporation fluxes and of their isotopic

14 composition. In addition, the data provide an evaluation of the formulae traditionally used for

15 deriving the isotopic composition of bare soil evaporated water vapor, and especially of the

16 relevance of the kinetic fractionation factor values proposed in the literature for free water

17 bodies (Merlivat and Jouzel, 1979; Cappa et al., 2003). We also propose estimations of this

18 kinetic fractionation factor and of its associated standard error with the experimental data.

19 Data interpretation was found to be very sensitive to the value of the isotopic composition of

20 the soil surface liquid water. It raises questions about the relevant sampling depth which is

21 required to properly estimate the isotopic composition of evaporated water vapor. This point

22 is studied more in details in Part II of a companion paper (Braud et al., 2009) which presents

23 the modeling of these experimental results using the SiSPAT_Isotope model. 


\subsection{Experimental set up}

The RUBIC IV reactor (Figures 1 and 2) was developed in order to determine the isotopic composition of the water vapor released by an evaporating soil and to monitor its time evolution as long as the soil was drying. The leak tight experimental set up allowed to inject directly a gas flow of dry air simultaneously over six evaporating soil columns and to continuously capture all the water vapor released by evaporation by cryoscopic trapping. Therefore, the only water vapor source was that of the evaporating soil columns, without any contamination from external sources in the laboratory. Furthermore, the cryoscopic trapping ensured that all the water vapor coming from the soil evaporation was completely trapped. In the design of the experimental set up, the following constraints were taken into account:

- A continuous non destructive sampling for the water vapor phase and a destructive sampling for the liquid phase within the soil columns. That implied to dismantle the soil columns at successive dates, cut them into slices and analyze the isotopic composition of all samples, as well as their gravimetric water content

- A leak tight experimental set up with regards to external contaminations and loss of vapor or water from the system through a leak

- The continuous measurement and the regulation of climatic variables

- The continuous measurement of the most important variables describing the moisture status of the soil (water pressure and water content)

The various components of the experimental set up are detailed below.

- Air circulation and cryoscopic trapping of the water vapor (Figure 2)

In order to ensure the tightness constraints, the reactor was built in Pyrex material. It was composed of six columns, $12 \mathrm{~cm}$ in diameter and $50 \mathrm{~cm}$ in height. An argon leak test was performed in order to verify that there were no leaks. A dry air flow was continuously flowing 
1 over the columns. The air flow, available in the laboratory was desiccated using two devices

2 in series:

3 - A pressured desiccating filter (DAS1 at $0.01 \mu \mathrm{m}$, Domnick Hunter), delivering a dew point

4 equivalent to $-40^{\circ} \mathrm{C}$ (Fig. 2 (a))

5 - A double cryoscopic trapping (Fig. 2 (b)) in an ethanol bath at $-80^{\circ} \mathrm{C}$ (Thermo-Neslab

6 CC100, Cryocool 1 free immersion cooler)

7 The dry air was then introduced into an expansion fence (Fig. 2 (c)) where the pressure was

8 put in equilibrium with the six columns (Fig. 2 (d)). The corresponding air pressure,

9 temperature and humidity (in order to verify that the air was dry as expected) were first

10 measured at this stage (Fig. 2 (e)). The dry air was then delivered individually to each soil

11 column. The output air, once modified by the evaporation from the soil, was directed

12 towards capacitive sensors measuring the partial pressure of the water vapor (leading to the

13 temperature and relative humidity of the air) (Fig. 2 (f)). The choice to measure the air

14 temperature and humidity above the columns at the outlet was dictated by the following:

15 preliminary measurements of the air relative humidity above the soil columns highlighted

16 some heterogeneity in the atmosphere. Therefore, it was difficult to have an identical

17 position of the sensors above each of the six columns, due to the size of the sensors. All the

18 heterogeneities were integrated by the measurement of the air temperature and relative

19 humidity at the outlet. The air was then directed to mass flow controllers (Fig. 2 (g)) which

20 regulated the vapor flux as function of a set point of the air humidity at the outlet of the

21 columns. For this purpose a Proportional Integral Derivative-type system, which allowed

22 accurate regulation of the relative humidity above the soil columns was used. Finally, two

23 Cryocools (Thermo-Neslab CC100) were cooling continuously a cryoscopic device (Fig. 2

24 (h)), allowing to trap the whole output water vapor. At the outlet of the cryocools, a 
1 capacitive sensor (Fig. 2 (i)) was controlling the residual water vapor content and

2 consequently the quality of the trapping.

- Continuously measured variables

4 A Campbell CR23X data logger and multiplexer AM 16/32 were used to record 44 variables

5 with a 15- min averaging time step. These variables were aimed at documenting the water

6 mass balance of the six columns and the soil moisture status of one of them, namely column

$7 \quad$ 1. The measured variables were:

8 - The air temperature and relative humidity at the outlet of the six columns (Vaisala HMP 45,

9 with an accuracy of $\pm 0.2{ }^{\circ} \mathrm{C}$ and $\pm 1 \%$ of relative humidity) (12 variables). The regulation of

10 the relative humidity of the atmosphere above the soil columns is the result of a compromise

11 between the evaporation flux and the flux of dry air flowing through the head space of the

12 columns. The value of the latter flux should not exceed $2.01 \mathrm{~min}^{-1}$ because of the isotopic risk

13 of fractionation of the water vapor related to the incomplete trapping of this vapor (Schoch-

14 Fisher et al., 1983). This constraint did not enable, initially, to reach a value lower than $80 \%$

15 for the relative humidity regulation. Then, as the evaporation flux decreased because of the

16 fall in the soil water content, it was necessary to decrease the value retained for the regulation

17 of the relative humidity. The values are provided in Table 1 and Figure 3.

18 - The air flow: six mass flow meters (Bronkhorst EL-Flow) were under control of the

19 previous hygrometers in order to regulate air humidity above the soil columns with an

20 accuracy of $0.00811 \mathrm{~min}^{-1}$ (6 variables)

21 - The column mass: column 1, where soil moisture status was monitored, was weighted using

22 a $30 \mathrm{~kg}$ Sartorius balance (model CP34001, accuracy $0.2 \mathrm{~g}$ ). The five other columns were

23 weighted by strain gauges (Tedea 1040 load cell, range $30 \mathrm{~kg}$, accuracy $4 \mathrm{~g}$ ) which were

24 calibrated by comparison with the Sartorius balance (6 variables). The data were filtered to

25 smooth the values 
1 - The temperature of the cryoscopic trapping down and upstream of the columns was

2 measured by thermocouples of $\mathrm{K}$-type (2 variables)

3 - The air temperature and residual air humidity were measured at the outlet of the cold traps

4 using capacitive sensors (Vaisala HMP45) (4 variables)

5 - The temperature of the room was measured using a Campbell T107 thermistance (1

6 variable)

7 - The atmospheric pressure was monitored using a Vaisala PT101B barometer. The absolute

8 pressure in the expansion fence (slightly put in over-pressure) was measured using an

$9 \quad$ Edwards EPS10 gauge (2 variables)

10 -The soil water pressure was measured in column 1 by using ceramic porous cups (SDEC

11220 ) of $2 \mathrm{~mm}$ in diameter and $20 \mathrm{~mm}$ in length, provided with nylon capillary tubes and

12 connected to pressure transducers. The calibration of the pressure transducers was carried out

13 by using the variation of a water column for the pressure below $100 \mathrm{hPa}$ and a SDEC

14 manometer between 100 and $600 \mathrm{hPa}$. The data were corrected from the air pressure

15 variations in the reactor. Three such porous cups were installed at $-2.5,-8$ and $-16 \mathrm{~cm}$ depths

16 (3 variables)

17 - Capacitive moisture probes (SDEC HMS 9000) positioned at $-2.5,-8,-16$ and $-24 \mathrm{~cm}$ depths were recording continuously the temperature and electric permittivity of the soil of column 1 . Conversion of the permittivity values into volumetric water content ones $\left(\left(\theta_{-2.5} ; \theta_{-8}\right.\right.$

$\left.20 ; \theta_{-16} ; \theta_{-24}\right)$ was performed using a calibration based on gravimetric sampling. The 21 temperature sensors were calibrated against a K-type thermocouple using a stat-controlled water bath ( 8 variables). In addition, some gravimetric samples were collected for the 0-2.5 and $2.5-5 \mathrm{~cm}$ soil layers at various dates to determine the evolution of the surface moisture 24 content and the isotopic composition of the liquid phase. The holes were then filled with 
1 wood dowels and the corresponding surface was removed from the evaporating surface of the

2 columns (note that this sampling required a temporary stop of the experiment).

- Filling of the soil columns

4 The soil used to fill the columns was a silt loam (18\% clay, $65 \%$ loam, $17 \%$ sand). It had been

5 collected at the field station of Lusignan $\left(41.44^{\circ} \mathrm{N}, 0.14^{\circ} \mathrm{W}\right)$, France. The water tightness

6 constraints did not allow the use of undisturbed soil columns. Therefore, the soil was oven-

7 dried and sieved at $2 \mathrm{~mm}$ to remove stones and coarse organic matter. In order to get a dry

8 bulk density closed to the in situ one $\left(\rho_{d}=1.4 \mathrm{~g} \mathrm{~cm}^{-3}\right)$, the soil was humidified using

9 demineralized water of known isotopic composition at a constant water content corresponding

10 to a gravimetric value of $0.14 \mathrm{~g} \mathrm{~g}^{-1}$. The columns were filled with wet soil by packing

11 successive thin layers of constant mass in order to obtain the same dry bulk density values

over each column height ( $35 \mathrm{~cm}$ of soil). The columns were closed at their base by clay

13 marbles and by filters to facilitate their water saturation. This was achieved by capillary rise

14 from the bottom of the columns up to the soil surface using connected tanks. At the end of the

15 saturation process, a water sample was taken at the surface and the bottom of each column to determine the isotopic composition of the water by mass spectrometry. Results given in Table 2 show a satisfying reproductibility of the initial conditions prevailing within all the columns.

19 The water samples were analyzed using mass spectrometers (OPTIMA, GV Instrument) to determine their content in oxygen 18.

21 During the first three months, the water vapor was trapped twice a day and then once a day as evaporation decreased. To determine the atmospheric water vapor isotope concentration, the

23 vapor was frozen out of a maximum air flow of $1.01 \mathrm{~min}^{-1}$ into a trap cooled at $-80^{\circ} \mathrm{C}$. 
1 The trapped vapor was analyzed using the $\mathrm{CO} 2$ equilibration technique to determine the

2 oxygen 18 composition of water. Estimated standard deviation for the samples of water vapor

3 was $0.1 \%$.

4 For the liquid phase of the soil samples, the water was distilled at $90^{\circ} \mathrm{C}$ under vacuum

5 conditions from the material into a trap cooled by liquid nitrogen. During the static vacuum

6 distillation used for extracting soil water, the recovery was higher than $98 \%$. Water content

7 was obtained from weight loss of soil during distillation. Isotopic contents of soil water were

8 corrected according to the distillation yield by a Rayleigh-type law (Araguas-Araguas et al.,

9 1995). Although all the extraction carried out during the experiment had an efficiency higher

10 than $98 \%$, a correction, ranging from 0 to $0.4 \%$ was still necessary. The vacuum distillation

11 technique provides accurate results, especially for soils with the highest water content. As

12 shown in Fig. 4, no significant differences were observed during the prior tests between the

13 isotopic composition of soil water, exfiltrated water and supply water. Indeed, the extraction

14 temperature has been kept at a low value $\left(90^{\circ} \mathrm{C}\right)$ in order to minimize the impact of the

15 immobile water distillation on the isotopic composition of the extracted soil water (Araguas-

16 Araguas et al., 1995).

17 Note that throughout the paper, isotope measurements will be expressed in " $\delta$ " notation, as

18 the deviation of the isotopic ratio in parts per thousand from that of the Vienna Standard

19 Mean Ocean Water (V-SMOW, Gonfiantini, 1978).

20 The experiment was launched on April 112005 at 12h 00 (Day of the Year: DoY 101) and

21 lasted 338 days. At successive dates during the drying process (Table 3), one of the columns

22 was dismantled. Soil slices were sampled throughout the profile and analyzed as described

23 above. The thickness of the samples was about $0.5 \mathrm{~cm}$ between the surface and $10 \mathrm{~cm}$ depth

24 and $1 \mathrm{~cm}$ below. 
1 The nomenclature and list of symbols used in the following of the paper are provided in

2 Appendix A.

3

\subsection{Calculation of the evaporation flux and correction of the reactor dynamics}

The evaporation flux was calculated using three methods (four for column 1) in order to verify mass conservation:

- $\underline{\text { Method } 1}$. The evaporation flux was calculated using the air temperature $T_{\text {out }}$, relative humidity $h_{\text {uout }}(-)$ and the mass flow $q_{\text {out }}\left(1 \mathrm{~min}^{-1}\right)$ at the outlet of the columns as:

$$
E=\rho_{a} \frac{e_{\text {aout }} q_{\text {out }}}{\left(P_{\exp }-e_{\text {aout }}\right) S_{\text {col }}}
$$

where $E\left(\mathrm{~kg} \mathrm{~m}^{-2} \mathrm{~s}^{-1}\right)$ is the water vapor flux; $q_{\text {out }}\left(\mathrm{m}^{3} \mathrm{~s}^{-1}\right)$ is the flow of water vapor;

$e_{\text {aout }}=f\left(T_{\text {out }}, h_{\text {uout }}\right)(\mathrm{Pa})$ is the water vapor pressure at the outlet of the column; $P_{\exp }(\mathrm{Pa})$ is the pressure in the expansion fence; $\rho_{a}\left(\mathrm{~kg} \mathrm{~m}^{-3}\right)$ is the water vapor volumetric mass and $S_{c o l}\left(\mathrm{~m}^{2}\right)$ is the evaporative surface of the column.

- Method 2. The method uses directly the continuous weighting of the columns. The evaporation flux was obtained from mass difference between two time steps, with a filtering of the results.

- Method 3. It was based on the weighting of the frozen vapor which was trapped at the outlet of the soil columns. The flux was obtained as the mass divided by the time step. Note that the time resolution of this method is coarser than methods 1 and 2, as water vapor was trapped twice or once a day.

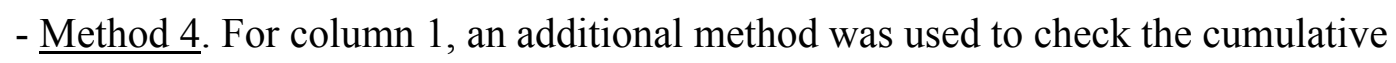
evaporation. It was based on the calculation of the change in soil water storage $\Delta S$ between a time step and the initial value. The soil water storage variation, $\Delta S(\mathrm{~m})$, was deduced as the integral of the soil water content using the following approximation: 


$$
1 \Delta S=0.35 \theta_{s}-\int_{z=0}^{z=-0.35} \theta(z) d z \approx 0.35 \theta_{s}-\frac{0.0525 \theta_{-2.5}+0.0675 \theta_{-8}+0.08 \theta_{-16}+0.15 \theta_{-24}}{0.35}
$$

2 where $\theta_{\mathrm{s}}\left(\mathrm{m}^{3} \mathrm{~m}^{-3}\right)$ is the volumetric water content at saturation, and $\theta_{-i}$ is the volumetric water

3 content at depth $-i$, the origin $(\mathrm{z}=0)$ being positively oriented downwards.

4 Appendix B provides the reactor equations. This Appendix shows that the approximation of 5 equality between the water flow at the outlet and the evaporation flux was valid throughout

6 the whole experiment. Appendix B also shows that the isotopic composition of the water

7 vapor measured at the outlet of the columns can be assumed equal to that of the evaporated

8 water vapor (Zimmerman et al., 1967).

9

\subsection{Isotopic composition of evaporated water vapor}

11 For a free water, Craig and Gordon (1965) proposed the following equation for the derivation

12 of the isotopic composition, $\delta_{i E}^{v}$, of the evaporated water vapor:

$$
\delta_{i E}^{v}=\frac{\left(\delta_{i s}^{l}+1\right)-h_{a}^{\prime}\left(\delta_{i a}^{v}+1\right)\left(\varepsilon_{e}+1\right)}{\left(\varepsilon_{e}+1\right)\left(\varepsilon_{K}+1\right)\left(1-h_{a}^{\prime}\right)}-1
$$

where $\delta_{i s}^{l}\left(\operatorname{resp} . \delta_{i a}^{v}\right)$ is the isotopic composition of the liquid water (resp. the ambient air water

15 vapor $), \varepsilon_{\mathrm{e}}=\left(1-\alpha_{e}\right)$ and $\varepsilon_{\mathrm{K}}=\left(1-\alpha_{K}\right)$. The equilibrium isotopic fractionation factor $\alpha_{e}=\frac{R_{i}^{l}}{R_{i}^{v}}=\frac{1}{\alpha_{e}^{*}}$

$(-)$ is defined as the ratio of the isotopic ratio in the liquid phase $R_{i}^{l}$ to the isotopic ratio in the

17 vapor phase $R_{i}^{v}$. Its expression is given by Majoube (1971) as a function of temperature $T(\mathrm{~K})$. $\alpha_{K}(-)$ is the so-called isotopic kinetic fractionation factor. It is related to the difference in

19 diffusivity between light and heavy water molecules (Merlivat, 1978). Finally $h_{a}^{\prime}$ is the air

20 relative humidity, normalized to the temperature of the water surface, given by:

$$
h_{a}^{\prime}=h_{a} \frac{\rho_{s a t}^{v}\left(T_{a}\right)}{\rho_{\text {sat }}^{v}\left(T_{s}\right)}
$$


1 where $T_{a}\left(\operatorname{resp} . T_{s}\right)$ is the air (resp. surface) temperature, $h_{a}(-)$ is the air relative humidity and

$2 \rho_{\text {sat }}^{v}(T)$ is the saturated volumetric mass of the water vapor $\left(\mathrm{kg} \mathrm{m}^{-3}\right)$. Therefore, Eq. (3) can be

3 rewritten in terms of isotopic ratio, equilibrium and kinetic fractionation factor:

4

$$
R_{i E}^{v}=\frac{1}{\alpha_{K}} \frac{\left(\alpha_{e}^{*} R_{i s}^{l}-R_{i a}^{v} h_{a}^{\prime}\right)}{\left(1-h_{a}^{\prime}\right)}
$$

This formula, established for free water, was shown to be valid for saturated soils by

Zimmerman et al. (1967) and is also widely used to derive the isotopic composition of transpired water vapor (i.e. Yakir and Strenberg, 2000). For an unsaturated soil, the extension of the Craig and Gordon (1965) approach leads to the following expression for the isotopic composition of the evaporated water vapor:

$$
R_{i E}^{v}=\frac{1}{\alpha_{K}} \frac{\left(\alpha_{e}^{*} R_{i s}^{l} h_{s}-R_{i a}^{v} h_{a}^{\prime}\right)}{\left(h_{s}-h_{a}^{\prime}\right)}
$$

where $h_{s}$ is the soil surface relative humidity (-). Braud et al. (2005a) provided the following expressions for the evaporation flux $E\left(\mathrm{~kg} \mathrm{~m}^{-2} \mathrm{~s}^{-1}\right)$ and the corresponding isotopic flux $E_{i}(\mathrm{~kg}$ $\left.\mathrm{m}^{-2} \mathrm{~s}^{-1}\right)$ :

$$
E=\frac{\rho_{a}}{r_{a}}\left(q_{s}-q_{a}\right)
$$

$$
E_{i}=\frac{\rho_{a}}{\alpha_{K} r_{a}} \frac{M_{i}}{M_{w}}\left(R_{i s}^{v} q_{s}-R_{i a}^{v} q_{a}\right)
$$

where $\rho_{a}\left(\mathrm{~kg} \mathrm{~m}^{-3}\right)$ is the air volumetric mass; $q_{s}$ and $q_{a}\left(\mathrm{~kg} \mathrm{~kg}^{-1}\right)$ are the specific humidity at the soil surface and in the atmosphere, respectively; $r_{a}\left(\mathrm{~s} \mathrm{~m}^{-1}\right)$ is the aerodynamic resistance to heat and water vapor transfer; $M_{i}$ and $M_{w}(\mathrm{~kg})$ are the molar mass of the isotopic species and of ordinary water, respectively; $R_{i s}^{v}$ and $R_{i a}^{v}$ are the isotopic ratio of the water vapor at the surface and in the atmosphere, respectively. Braud et al. (2005a) assumed that the liquid isotopic composition $R_{i s}^{l}$ at the soil surface was in equilibrium with the water vapor, leading to: 
$1 \quad R_{i}^{v}=\alpha_{e}^{*} R_{i}^{l}$

2 The surface isotopic flux was thus rewritten as:

$$
E_{i}=\frac{\rho_{a}}{\alpha_{K} r_{a}} \frac{M_{i}}{M_{w}}\left(\alpha_{e}^{*} R_{i s}^{l} q_{s}-R_{i a}^{v} q_{a}\right)
$$

4 The ratio of the isotope and water vapor flux is related to the isotopic ratio $R_{i E}^{v}$ of the

5 evaporating water vapor through:

6

$$
\frac{E_{i}}{E}=\frac{M_{i}}{M_{w}} R_{i E}^{v}
$$

7 Combining Eqs (7), (8) and (11), leads to the following equation:

8

$$
\frac{E_{i}}{E}=\frac{1}{\alpha_{K}} \frac{M_{i}}{M_{w}} \frac{\left(\alpha_{e}^{*} R_{i s}^{l} q_{s}-R_{i a}^{v} q_{a}\right)}{\left(q_{s}-q_{a}\right)}=\frac{M_{i}}{M_{w}} R_{i E}^{v}
$$

9 from which the isotopic ratio of the evaporating water vapor can be deduced:

$$
R_{i E}^{v}=\frac{1}{\alpha_{K}} \frac{\left(\alpha_{e}^{*} R_{i s}^{l} q_{s}-R_{i a}^{v} q_{a}\right)}{\left(q_{s}-q_{a}\right)}
$$

11 The difference between (13) and (6) is due to the fact that we expressed the gradient in water vapor density between the surface and the ambient air using the specific humidity instead of the relative humidity: $\rho_{s}^{v}-\rho_{a}^{v}=\rho_{\text {air }}\left(q_{s}-q_{a}\right)$, but both expressions are strictly equivalent.

14 In the following, Eq. (6) will be used as it is more commonly encountered in the isotopic literature.

16 The experiment provided the data required to use Eq. (6). As a matter of fact, the soil surface temperature was measured at $-2.5 \mathrm{~cm}$. The gravimetric measurements of the $0-2.5 \mathrm{~cm}$ layer were converted into volumetric water content from the measured values of dry bulk density (Table 2). The volumetric water content was converted into water pressure $h$ using the soil retention curve fitted to the Van Genuchten (1980) expression. The points were based on measured values of soil water content and soil water pressure at $-2.5 \mathrm{~cm}$ soil depth (Fig. 5). 
1 From the soil water pressure $h$, the soil surface relative humidity $h_{s}$ was deduced from the

2 Kelvin law:

3

$$
h_{s}=\exp \left(-\frac{g h}{R T_{s}}\right)
$$

4 In Eq. (14), $g\left(\mathrm{~m}^{2} \mathrm{~s}^{-1}\right)$ is the acceleration of gravity and $R=461.5 \mathrm{~J} \mathrm{~kg}^{-1}$ is the perfect gas constant for vapor and $T_{S}(\mathrm{~K})$ is the soil surface temperature. The air temperature and humidity of the air above the soil column were assumed to be equal to those measured at the outlet of the column. As mentioned in section 2.1, the outlet measurements were integrating all the heterogeneities in the climatic variables above the soil column and thus, could be considered as representative of the values above the soil columns. The last quantity to estimate was the isotopic ratio of the soil surface liquid phase. This was achieved by the use of the isotopic composition of the gravimetric samples mentioned above. All the data are provided in Table 4. Finally, a value of the kinetic fractionation factor had to be prescribed. Various values from the literature were tested. For molecular diffusion conditions, Merlivat (1978) proposed 1.0285 for oxygen 18, whereas Cappa et al. (2003) suggested 1.03188.

Under laminar situations, the kinetic fractionation factor is assumed to be $\left(\alpha_{K}\right)^{2 / 3}$ and $\left(\alpha_{K}\right)^{1 / 2}$ for turbulent conditions (Dongmann et al., 1974), leading respectively to 1.0189 and 1.014, for oxygen 18 with the Merlivat (1978) values. The values calculated using Eq. (6) were compared with the measured ones for various estimates of the kinetic fractionation factor (see the results section). The standard error in the estimation of $R_{i E}^{v}$ is also provided. The details of its calculation are given in Appendix C, using an extension of the approach proposed by Phillips and Gregg (2001).

There was no agreement between Eq. (6) and the measured value of the isotopic composition of the evaporated water vapor. Therefore, the value of the isotopic composition of the soil 
1 surface liquid water, $R_{i s}^{l}$ which would be required so that both values match was also

2 calculated as

$3 \quad R_{i s}^{l}=\frac{R_{\text {iout }}^{v}\left(h_{s} \alpha_{K}-h_{a}^{\prime}\left(\alpha_{K}-1\right)\right)}{\alpha_{e}^{*} h_{s}}$

4 where $R_{\text {iout }}^{v}$ is the isotopic composition of the water vapor at the outlet of the columns.

5 Appendix D provides the corresponding error calculation.

6 Note that Eq. (15) is similar to the one proposed by Barnes and Allison (1983) for the

7 calculation of the peak value in the soil water isotopic composition profile. The major

8 difference is that, contrarily to Barnes and Allison (1983) conditions, the soil is not under

9 permanent regime in the condition of our experiment. Thus the isotopic composition of the

10 evaporated water vapor is not equal to that of the capillary rises/alimentation water and was

11 measured.

12

\subsection{Estimation of the kinetic fractionation factor}

Appendix B shows that, for our experimental conditions, the isotopic composition of the evaporating water vapor $R_{i E}^{v}$ and the water vapor above the soil column $R_{i a}^{v}$ as well as at the outlet $R_{\text {iout }}^{v}$ were the same. Therefore, the kinetic fractionation factor can also be deduced from Eq. (15) as:

$$
\alpha_{K}=\frac{\left(\alpha_{e}^{*} R_{i s}^{l} h_{s}-R_{\text {iout }}^{v} h_{a}^{\prime}\right)}{\left(h_{s}-h_{a}^{\prime}\right) R_{\text {iout }}^{v}}
$$

The data of the experiment as described in section 2.3 were used to perform these calculations. The standard error in the estimation of $\alpha_{K}$ is also given. The details of its calculation are provided in Appendix E.

\section{Results and discussion}




\subsection{Evaporation flux}

2 Figure 6 shows two examples (for columns 1 and 4 ) of the comparison between the

3 cumulative and instantaneous evaporation flux using the four (three) methods described in

4 section 2.2. Table 5 provides the values of the cumulative evaporation for the six columns and

5 all the methods. It shows that, apart from the $\Delta S$ method, the agreement between the methods

6 is very satisfying. Differences on cumulative evaporation are less than $5 \mathrm{~mm}$ between the

7 methods. Figure 6 also shows that the dynamics of the fluxes is similar between the methods.

8 Figure 7 presents the measured evaporation fluxes and the corresponding cumulative

9 evaporation, calculated by method 1, for the six columns. Although, the filling of the soil

10 columns was carefully conducted, a certain degree of variability between them can be

11 observed. This means a posteriori that the flux measurement of each of the six columns was necessary for the modeling and correct data interpretation. Several phases in the evaporation can be distinguished. In a first phase (between DoY 101 and 130), the evaporation flux is almost constant (fluctuations are linked with the diurnal variations of the air temperature (see Figure 3 for the example of column 1), which was not regulated within the room). In a second

16 phase, the flux decreases regularly up to DoY 207 as long as the soil surface is drying (volumetric water content at $-2.5 \mathrm{~cm}$, not shown). On DoY 207, the set point of air humidity was decreased from $80 \%$ to $60 \%$ in order to maintain the air flow above the columns (and to avoid a contamination of cold traps by a back flow of water vapor coming from the laboratory). This provokes a drastic increase of the evaporation flux and then another

21 continuous decrease. The other changes in the prescribed relative humidity do not produce such peaks. 
1 Table 2 shows that the saturation of the soil columns was in general correctly achieved with

2 an isotopic composition of the liquid water which was equal, within $\pm 0.2 \%$, at the surface

3 and at the bottom of the column. In general, the latter were also equal, within $\pm 0.2 \%$, to the

4 isotopic composition of the saturation water which was $-6.4 \%$. It was not the case for

5 columns 4 and 5 for which the isotopic composition of the liquid water at the bottom were 0.5

6 to $0.9 \%$ higher than that of the saturation water This difference is not obvious to explain: it

7 may be caused by leaks at the base of the soil column, isotopic variation in the source water,

8 mixing with residual water... This difference does not affect data interpretation because we

9 used the measured values for all the calculations and simulations. Figure 8 provides the water

10 content and oxygen 18 isotopic ratio profiles of the six columns at dates they were

11 dismantled. It shows the progressive drying of the soil column until the soil surface reaches an

12 almost zero residual water content. The whole soil column is affected by the drying, and all

13 depths are participating to evaporation. The isotopic ratio profiles show a progressive isotopic

14 enrichment located close to the surface at the beginning of the drying process. After 163 days

15 of drying (DoD), a back diffusion is observed with a peak at $-2.5 \mathrm{~cm}$. The depth of the peak

16 increases up to $-4 \mathrm{~cm}$ after $235 \mathrm{DoD}$ and reached $-10 \mathrm{~cm}$ after $338 \mathrm{DoD}$ of drying. As

17 proposed by Barnes and Allison (1983) and verified by Braud et al. (2005a) using the

18 SiSPAT_Isotope model, the depth of the isotopic ratio peak can be associated with the depth

19 of the evaporation front, i.e. the depth above which water vapor transport is dominant as

20 compared to the liquid one.

\subsection{Isotopic composition of the evaporated water vapor}

The oxygen 18 isotopic composition of the water vapor at the outlet of the columns is shown

in Fig. 9. As observed for the evaporation flux, there is certain variability amongst the six 
1 of the evaporated water vapor of each soil column separately. The shape of the various curves

2 is comparable. A rapid increase of the isotopic composition of the evaporated water vapor is

3 first observed. Then a stabilization around an almost constant value can be noticed. The latter

4 is close to the value of the initial water $(-6.4 \%)$. Then, the isotopic composition of the

5 evaporated water vapor progressively decreases. This decrease coincides with the apparition

6 of back diffusion close to the surface, leading to the decrease of the soil surface liquid

7 isotopic composition. This impoverishment of the isotopic composition of the evaporated

8 water vapor increases as long as the soil dries. At the end of the experiment, a stabilization

9 around a value of about $-14 \%$ can be observed.

\subsection{Estimation of the isotopic composition of the evaporated water vapor}

12 Table 6 provides the comparison between the measured and calculated (using Eq. (6)) oxygen

1318 isotopic composition of the evaporated water vapor for various values of the kinetic

14 fractionation factor. Figures 10 and 11 show the comparison of the estimated and measured

values for $\alpha_{K}=1.0189$ (laminar diffusion). Error bars on the estimation, as well as the

minimum and maximum values estimated from Eq. (C.23 in Appendix C) are also provided.

In Fig. 10, errors on the measured variables are assumed to be due to analytical or sensors accuracy only. In Fig. 11, sampling errors are considered. For both cases, the retained errors on the measured variables are given in Table 7.

20 Table 6 and Figs 10 and 11 show that, whatever the value retained for the kinetic fractionation

21 factor, the calculated isotopic composition of the evaporated water vapor is much lower than the measured one. Figure 10 shows that analytical and sensors errors alone cannot explain this discrepancy as their use leads to very small standard errors. On the other hand, when sampling errors are considered (Fig. 11), the confidence intervals sometimes encompass the measured values. In the remaining of the paper, only standards errors calculated using 
1 sampling errors will be presented, as they provide more realistic standard error values. Figure

212 provides the decomposition of the sources of errors, including (bottom) or excluding (top)

3 errors on the kinetic fractionation factor. It shows that error on the isotopic composition of the

4 soil surface liquid water is the major source of uncertainty in the estimation of the isotopic

5 composition of the evaporated water using Eq. (6). Error on the soil surface water content

6 becomes significant when the soil becomes very dry. When error on the kinetic fractionation

7 factor is taken into account, it becomes the major source of uncertainty.

8 Table 6 and Figs 10 and 11 allow comparing the results for 6 dates with soil samples taken

9 over different depths (grey lines). When the sampling depth is the smallest, the calculated

10 isotopic composition of the evaporated water vapor is closer to the measured one before the

11 apparition of the back diffusion (DoY 132, 154 and 192). In this case, a lower sampling depth

12 is associated with a higher value of the soil isotopic ratio and to a higher value of the isotopic

13 composition of the evaporated water (the partial derivative is positive under evaporation - see

14 Eq. (C.20) in Appendix C). Therefore, when there is no back diffusion, the isotopic

15 composition of the evaporated water seems to be controlled by the very soil surface isotopic

16 ratio, which is difficult to sample. On the other hand, when back diffusion has taken place

17 (DoY 264, 336, 439), the calculated isotopic composition of the evaporated water vapor is

18 closer to the measured one when the thicker sampling depth is used. In case of back diffusion,

19 the very soil surface isotopic composition of the liquid water does not seem to be the one

20 controlling the isotopic composition of the evaporated water vapor, which appears to be

21 related to the isotopic composition of the liquid water in deeper layers.

22 To investigate this point further, Table 8 provides the isotopic composition of the soil surface

23 liquid water, given by Eq. (15), which would be required to match the measured and

24 calculated values of the isotopic composition of the evaporated water. Results are provided

25 for several values of the kinetic fractionation factor. The corresponding standard errors 
1 (taking into account or not errors on the kinetic fractionation factor) are also given and the

2 results are plotted in Fig. 13. Figure 14 shows the contribution of the various sources of errors

3 to the total error. Table 8 shows that the calculated values for the isotopic composition of the

4 soil liquid water are systematically higher than the values measured over the $0-2.5$ or $0-0.5$

$5 \mathrm{~cm}$ depth, although the error bars encompass the measured values. The calculated values are

6 close to the maximum value observed in the measured isotopic soil profiles (see Fig. 8 and

7 Table 8), which corresponds to the evaporation front. The calculated values decrease when the

8 kinetic fractionation factor decreases. Before the appearance of back diffusion (before DoY

9 193), the measured maximum are closer to the values calculated with the lowest kinetic

10 fractionation factor value. After the appearance of back diffusion (after DoY 193), they are

11 closer to values calculated with a kinetic fractionation factor of 1.0189. The standard error is

12 generally between 2 and $4 \%$, but increased up to $7-8 \%$ when error on the kinetic

13 fractionation factor is considered (Table 8). When the kinetic fractionation factor is not taken

14 into account, the contribution of errors on the air and soil temperature, air relative humidity

15 and isotopic composition of the evaporated water contribute equally well to the total error (see

16 Fig. 14). Errors on the soil surface water content become significant when the soil is very dry.

17 When error on the kinetic fractionation factor is included, Fig.14 shows that it has the same

18 contribution as the other factors before the appearance of the water vapor back diffusion

19 (before DoY 193). After this date, it becomes the major source of uncertainty.

20 The analysis presented in this section shows that the isotopic composition of the evaporated

21 water vapor strongly depends on the soil isotopic composition of the soil liquid water. Before

22 back diffusion, this isotopic composition seems to be controlled by the isotopic composition

23 of the soil liquid water at the very surface. Such depth cannot be sampled up to now. When

24 back diffusion has taken place, the picture still remains unclear. This point will be further

25 analyzed in the companion paper using the modeling approach, especially to determine if a 
1 relationship with the depth of the evaporating front (depth of the peak isotopic ratio in the

2 soil) can be evidenced.

3 The results also suggest that the value of the kinetic fractionation factor which should be used

4 in Eq. (6) is variable in time, with a notable difference before and after the appearance of back

5 diffusion. This hypothesis is further examined in the following section where we try to

6 estimate the value of the kinetic fractionation factor which ensures that measured and

7 calculated (Eq. (6)) values of the isotopic composition of the evaporated water are equal. For

8 this calculation the measured values (Table 4) of the isotopic composition of the soil surface

9 liquid water were used, although the calculations performed in this section suggest that they

10 might not be relevant all the time.

11

\subsection{Estimation of the kinetic fractionation factor}

Table 9 provides the values of the kinetic fractionation factor calculated using Eq. (16) for oxygen 18. It also provides estimates of the standard error, minimum and maximum estimated values using the method described in Appendix E, when considering sampling errors. Figure 15 gives the contribution of the various sources of errors to the total standard error. Table 9 shows that the calculation can lead to negative values of the kinetic fractionation factor, which is of course inconsistent with its definition. This result must be mitigated given the large uncertainty. Furthermore, the kinetic fractionation factor is an increasing function of the soil surface isotopic composition of water (Eq. E.12 in Appendix E). Therefore, the highest values of the soil surface isotopic ratio provide the highest estimates of the kinetic fractionation factor. Before the establishment of back diffusion (before DoY 193), the isotopic composition of the soil surface water is underestimated if thicker layers are taken into account (see also the comparison between the results for various depths in Table 9, grey lines). The best estimates of the kinetic fractionation factors would therefore be the upper bound of the estimation. After 
1 the establishment of back diffusion (after DoY 193), the results are inverted, as also discussed

2 in section 3.4. Higher values of the estimated kinetic fractionation factor are obtained when

3 the soil surface isotopic ratio is estimated with thicker layers (grey lines in Table 9). The

4 estimations of the kinetic fractionation factor provided in Table 9 are in general lower than the

5 values commonly used in the literature (14 to $28.5 \%$, Merlivat, 1978) for a free water

6 surface, but the uncertainty is large. Figure 15 shows that the uncertainty on the isotopic

7 composition of the soil liquid water is the major source of uncertainty in the calculation.

8 After back diffusion (last three lines of Table 9), the kinetic fractionation factor was also

9 estimated using the maximum values of soil water content and isotopic ratio encountered in

10 the profile and corresponding to the evaporation front. In this case, the calculated values are

11 well within the range of literature values (Merlivat, 1978) and confirms that, after back

12 diffusion, the isotopic composition of the evaporated water vapor seems to be linked to the 13 isotopic ratio at the evaporation front.

\section{Conclusions}

16 In Part I of this paper, we have presented a novel experiment which allows to measure

17 simultaneously the evaporation flux and the isotopic composition of the evaporated water

18 under controlled conditions for bare soil. We compared the measured isotopic composition of

19 the evaporated water with traditional estimates. The results show that, using experimental

20 data, none of the kinetic fractionation factor values encountered in the literature was able to

21 give results in agreement with the measured ones. The error analysis also showed the high

22 sensitivity of the results to the isotopic composition of the very soil surface liquid water. This

23 raises question about the sampling depth required to get satisfactory results. Our results

24 suggest that, when back diffusion has not occurred, the sampling depth should be as small as

25 possible. On the other hand, when back diffusion has taken place (and the top soil profile 
1 water movement takes place in the vapor phase), the isotopic composition of the evaporated

2 water seems to be controlled by the value at the peak (evaporation front). If this results can be

3 easily understood before back diffusion occurs, the relationship with the depth of the

4 evaporation front requires further investigation. This is done in Part II of a companion paper

5 (Braud et al., 2009) dedicated to the modeling of the experimental results using the

6 SiSPAT_Isotope model of Braud et al. (2005a).

7 The data measured during the experiment allowed us to propose estimates of the kinetic

8 fractionation factor of an evaporating soil. The uncertainty of the estimate is very large, as

9 before, due to large uncertainties in the sampling depth required for the estimation of the

10 isotopic composition of the soil liquid water. Although the average of the estimated values are

11 lower than the values of Merlivat (1978) or Cappa et al. (2003) proposed in the literature and

12 obtained for free surface water, results analysis suggest that a higher accuracy in the

13 experimental design should be required to get a reliable estimate of the kinetic fractionation

14 factor. Improvements must address the soil sampling to get a higher vertical resolution and

15 also a better control of temperature in addition to the relative air humidity, so that the water

16 vapor pressure, which controls the evaporation is more constant in time.

17

\section{Acknowledgements}

The "Programme National de Recherche en Hydrologie" of the French "ECosphère

COntinentale" program is acknowledged for providing the financial support of the experiment.

Appendix A : Nomenclature of the variables used in the core of the paper (Appendices excluded)

DoD Day of Drying

DoY Day of the Year

$e_{\text {aout }} \quad$ Water vapor pressure at the outlet of the column $(\mathrm{Pa})$

$E \quad$ Water vapor or evaporation flux $\left(\mathrm{kg} \mathrm{m}^{-2} \mathrm{~s}^{-1}\right)$

$E_{i} \quad$ Isotopic water vapor flux at the surface $\left(\mathrm{kg} \mathrm{m}^{-3}\right)$

$g \quad$ Acceleration of gravity $\left(\mathrm{m}^{2} \mathrm{~s}^{-1}\right)$ 


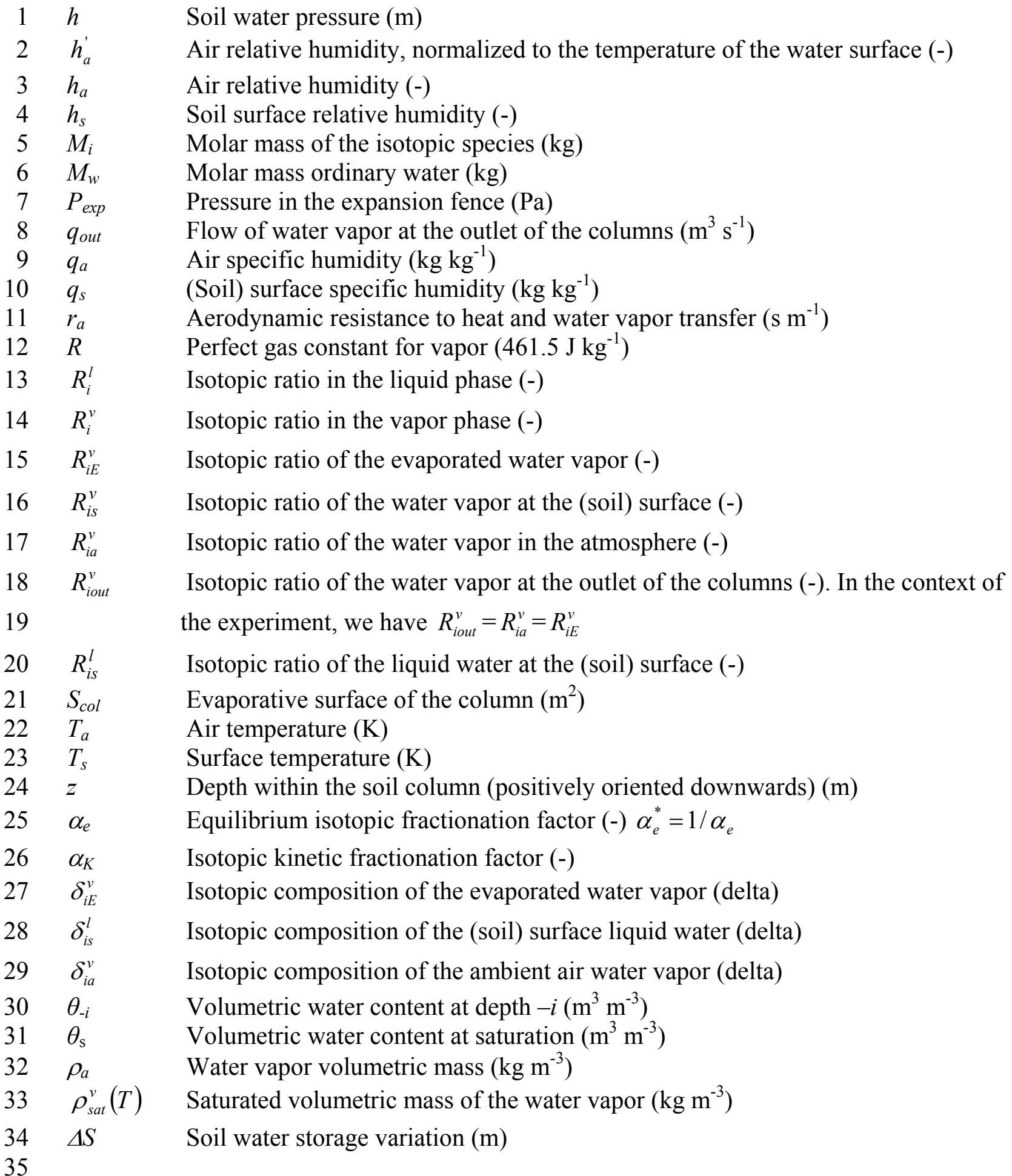

Appendix B : Equations of the RUBIC IV reactor

37 Lets consider $q_{\text {in }}\left(\mathrm{m}^{3} \mathrm{~s}^{-1}\right)$ the incoming air flow, $C_{\text {in }}^{v}\left(\mathrm{~kg} \mathrm{~m}^{-3}\right)$ its concentration in water vapor and $R_{i_{-} \text {in }}^{v}\left(\mathrm{~m}^{3} \mathrm{~s}^{-1}\right)$ its isotopic ratio. The notations are: $q_{\text {out }}, C_{\text {out }}^{v}$, and $R_{i_{-} \text {out }}^{v}$ for the air at the

39 outlet of the column. $\Phi_{e v}\left(\mathrm{~kg} \mathrm{~s}^{-1}\right)$ is the water vapor flux released by the soil and $R_{i E}^{v}$ its 
1 isotopic ratio. $V_{c}\left(\mathrm{~m}^{3}\right)$ is the air volume above the soil column, $C_{c o l}^{v}\left(\mathrm{~kg} \mathrm{~m}^{-3}\right)$ its water vapor

2 concentration and $R_{i_{-} c o l}^{v}$ its isotopic ratio.

3 The mass balance equation of the air above the soil column can be written as:

$4 \quad \frac{d\left(V_{c} C_{c o l}^{v}\right)}{d t}=q_{i n} C_{i n}^{v}+\phi_{e v}-q_{o u t} C_{o u t}^{v}$

5 Assuming that the reactor is a perfect mixing device and that the water vapor concentration

6 above the column is instantaneously equal to that of the outlet vapor, i.e. $C_{c o l}^{v}=C_{o u t}^{v}$, Eq.

7 (B.1) can be rewritten as:

8

$$
\frac{d C_{o u t}^{v}}{C_{o u t}^{v}-\frac{q_{\text {in }} C_{\text {in }}^{v}+\phi_{\text {ev }}}{q_{\text {out }}}}=-\frac{q_{\text {out }} d t}{V_{c}}
$$

9 Considering that between $t$ and $t+\Delta t, q_{i n}, q_{o u t}$ and $\Phi_{e v}$ fluxes are constant, the integration of 10 the equation leads to:

11

$$
C_{\text {out }}^{v}=\frac{q_{\text {in }} C_{\text {in }}^{v}+\phi_{\text {ev }}}{q_{\text {out }}}+\left(C_{\text {out }}^{v 0}-\frac{q_{\text {in }} C_{\text {in }}^{v}+\phi_{\text {ev }}}{q_{\text {out }}}\right) \exp \left(-\frac{q_{\text {out }} \Delta t}{V_{c}}\right)
$$

12 where the ${ }^{0}$ superscript refers to the value at time $t$.

13 The concentration at the outlet is measured and the unknown in Eq. (B.3) is the evaporation

14 flux which is obtained by rearranging Eq. (B.3) as:

15

$$
\phi_{\text {ev }}=q_{\text {out }} C_{\text {out }}^{v} \frac{1-\frac{q_{\text {in }} C_{\text {in }}^{v}}{q_{\text {out }} C_{\text {out }}^{v}}-\left(\frac{C_{\text {vout }}^{v 0}}{C_{\text {out }}^{v}}-\frac{q_{\text {in }} C_{\text {in }}^{v}}{q_{\text {out }} C_{\text {out }}^{v}}\right) \exp \left(-\frac{q_{\text {out }} \Delta t}{V_{c}}\right)}{1-\exp \left(-\frac{q_{\text {out }} \Delta t}{V_{c}}\right)}
$$

16 Similar equations can be written for the isotopic species. They lead to:

$$
\frac{d\left(V_{c} C_{\text {col }}^{v} R_{i_{-} \text {col }}^{v}\right)}{d t}=q_{\text {in }} C_{\text {in }}^{v} R_{i_{-} \text {in }}^{v}+\phi_{e v} R_{i E}^{v}-q_{\text {out }} C_{\text {out }}^{v} R_{i_{-} \text {out }}^{v}
$$


1

$$
\frac{d\left(C_{\text {out }}^{v} R_{i_{-} \text {out }}^{v}\right)}{C_{\text {out }}^{v} R_{i_{-} \text {out }}^{v}-\frac{q_{\text {in }} C_{\text {in }}^{v} R_{i_{-} \text {in }}^{v}+\phi_{e v} R_{\text {iE }}^{v}}{q_{\text {out }}}}=-\frac{q_{\text {out }} d t}{V_{c}}
$$

$$
C_{\text {out }}^{v} R_{i_{-} \text {out }}^{v}=\frac{q_{\text {in }} C_{\text {in }}^{v} R_{i_{-} \text {in }}^{v}+\phi_{\text {ev }} R_{i E^{v}}^{v}}{q_{\text {out }}}+\left(C_{\text {vout }}^{v 0} R_{i_{-} \text {out }}^{v 0}-\frac{q_{\text {in }} C_{\text {in }}^{v} R_{i_{-} \text {in }}^{v}+\phi_{\text {ev }} R_{i E}^{v}}{q_{\text {out }}}\right) \exp \left(-\frac{q_{\text {out }} \Delta t}{V_{c}}\right)
$$

4 In Eqs (B.4) and (B.8), the $\exp \left(-\frac{q_{\text {out }} \Delta t}{V_{c}}\right)$ term takes into account a possible inertia of the reactor in transmitting the evaporation flux towards the outlet.

With the experimental conditions prevailing in the reactor, the incoming air was dry, therefore $C_{i n}^{v}=0$. The air volume above the column was $\mathrm{V}_{\mathrm{c}}=\pi \mathrm{R}^{2} \mathrm{H}=1.13110^{-3} \mathrm{~m}^{3}$, with $R=0.06 \mathrm{~m}$ for the radius and $H=0.1 \mathrm{~m}$ for the height above the soil surface. The integration time was $\Delta t=900 \mathrm{~s}, q_{\text {out }}$ was ranging between 0.5 and $0.151 \mathrm{~min}^{-1}$, i.e. 8.33 and $2.510^{-6} \mathrm{~m}^{3} \mathrm{~s}^{-1}$.

10 Therefore the exponential term $\exp \left(-\frac{q_{\text {out }} \Delta t}{V_{c}}\right)$ was ranging between $1.3210^{-3}$ at the beginning 11 of the experiment to 0.137 at the end. The calculation of the evaporation flux with Eq. (B.4) showed that the correction was negligible with a difference in cumulated evaporation of less than $0.1 \mathrm{~mm}$. For the isotopic trapping, the time step was $\Delta t=86400 \mathrm{~s}$, therefore the same exponential term was close to zero. Therefore, for the conditions of the experiment, the following approximations:

$$
\phi_{\text {ev }}=q_{\text {out }} C_{\text {out }}^{v}
$$

(A.9) and

$$
R_{i E}^{v}=R_{o u t}^{v}
$$


2 Appendix C: Derivation of standard error for the estimated isotopic composition of the

3 evaporated water vapor

4 The isotopic composition of the evaporated water vapor is given by Eq. (6)

$$
R_{i E}^{v}=\frac{1}{\alpha_{K}} \frac{\left(\alpha_{e}^{*} R_{i s}^{l} h_{s}-R_{i a}^{v} h_{a}^{\prime}\right)}{\left(h_{s}-h_{a}^{\prime}\right)}
$$

6 with $R_{i a}^{v}=R_{\text {iout }}^{v}$ in the context of the experiment. The standard error can be obtained using an

7 extension of the formula proposed by Phillips and Gregg (2001). The result of Eq. (C.1)

8 depends on errors on the measurements of the air temperature and humidity $T_{a}$ and $h_{a}$, the soil

9 temperature $T_{s}$, the soil surface water content $\theta$, the isotopic composition of the soil surface

10 liquid water $\delta_{i s}^{l}$ and of the water vapor above the soil column $\delta_{i a}^{v}$. We can also take into

11 account the error on the kinetic fractionation factor $\alpha_{K}$ (last term in parentheses in Eq. (C.2)).

12 Assuming that the errors on all these factors are independent, the standard error $\sigma_{R_{i E}^{v}}$ can be

13 expressed as:

14

$$
\begin{aligned}
\sigma_{R_{i E}^{v}}^{2} & =\left(\frac{\partial R_{i E}^{v}}{\partial T_{s}}\right)^{2} \sigma_{T_{s}}^{2}+\left(\frac{\partial R_{i E}^{v}}{\partial T_{a}}\right)^{2} \sigma_{T_{a}}^{2}+\left(\frac{\partial R_{i E}^{v}}{\partial h_{a}}\right)^{2} \sigma_{h a}^{2}+\left(\frac{\partial R_{i E}^{v}}{\partial \delta_{i s}^{l}}\right)^{2} \sigma_{\delta_{i s}^{l}}^{2}+\left(\frac{\partial R_{i E}^{v}}{\partial \delta_{i a}^{v}}\right)^{2} \sigma_{\delta_{i a}^{v}}^{2}+ \\
& +\left(\frac{\partial R_{i E}^{v}}{\partial \theta}\right)^{2} \sigma_{\theta}^{2}+\left(\left(\frac{\partial R_{i E}^{v}}{\partial \alpha_{K}}\right)^{2} \sigma_{\alpha_{K}}^{2}\right)
\end{aligned}
$$

15 The partial derivatives of Eq. (C.2) can be obtained using the chain rules:

$$
\frac{\partial R_{i E}^{v}}{\partial T_{s}}=\frac{\partial R_{i E}^{v}}{\partial \alpha_{e}^{*}} \frac{\partial \alpha_{e}^{*}}{\partial T_{s}}+\frac{\partial R_{i E}^{v}}{\partial h_{a}^{\prime}} \frac{\partial h_{a}^{\prime}}{\partial T_{s}}
$$

$$
\frac{\partial R_{i E}^{v}}{\partial h_{a}}=\frac{\partial R_{i E}^{v}}{\partial h_{a}^{\prime}} \frac{\partial h_{a}^{\prime}}{\partial h_{a}}
$$

$$
\frac{\partial R_{i E}^{v}}{\partial \delta_{i a}^{v}}=\frac{\partial R_{i E}^{v}}{\partial R_{i a}^{v}} \frac{\partial R_{i a}^{v}}{\partial \delta_{i a}^{v}}
$$

$$
\begin{gathered}
\frac{\partial R_{i E}^{v}}{\partial T_{a}}=\frac{\partial R_{i E}^{v}}{\partial h_{a}^{\prime}} \frac{\partial h_{a}^{\prime}}{\partial T_{a}}(\mathrm{C} .4) \\
\frac{\partial R_{i E}^{v}}{\partial \delta_{i s}^{l}}=\frac{\partial R_{i E}^{v}}{\partial R_{i s}^{l}} \frac{\partial R_{i s}^{l}}{\partial \delta_{i s}^{l}}(\mathrm{C} . \\
\frac{\partial R_{i E}^{v}}{\partial \theta}=\frac{\partial R_{i E}^{v}}{\partial h_{s}} \frac{\partial h_{s}}{\partial h} \frac{\partial h}{\partial \theta}
\end{gathered}
$$


1 The partial derivatives appearing in these expressions are given below:

$\begin{aligned} 2 & \frac{\partial R_{i E}^{v}}{\partial \alpha_{e}^{*}}=\frac{1}{\alpha_{K}} \frac{R_{i s}^{l} h_{s}}{\left(h_{s}-h_{a}^{\prime}\right)}(\text { C.9) } \\ 3 & \alpha_{e}^{*}\left(T_{s}\right)=\exp \left(-\left[\frac{a}{T_{s}^{2}}+\frac{b}{T_{s}}+c\right]\right)\end{aligned}$ $\frac{\partial \alpha_{e}^{*}}{\partial T_{s}}=\alpha_{e}^{*}\left(\frac{2 a}{T_{s}^{3}}+\frac{b}{T_{s}^{2}}\right)(\mathrm{C} .10)$

4 with:

$5\left\{\begin{array}{l}a=1137 \\ b=-0.4156 \\ c=-0.0020667\end{array} \quad\right.$ for $\mathrm{H}_{2}{ }^{18} \mathrm{O}$

$6 \quad \frac{\partial R_{i E}^{v}}{\partial h_{a}^{\prime}}=\frac{1}{\alpha_{K}} \frac{\left(\alpha_{e}^{*} R_{i s}^{l}-R_{i a}^{v}\right) h_{s}}{\left(h_{s}-h_{a}^{\prime}\right)^{2}}$

$7 \quad \frac{\partial h_{a}^{\prime}}{\partial T_{a}}=-h_{a}^{\prime}\left(\frac{1}{T_{a}}-\frac{1}{e_{s a t}\left(T_{a}\right)} \frac{d e_{s a t}\left(T_{a}\right)}{d T_{a}}\right)$

(C.14) $\quad \frac{\partial h_{a}^{\prime}}{\partial h_{a}}=\frac{h_{a}^{\prime}}{h_{a}}$

$8 \quad \frac{\partial R_{i E}^{v}}{\partial h_{s}}=-\frac{1}{\alpha_{K}} \frac{\left(\alpha_{e}^{*} R_{i s}^{l}-R_{i a}^{v}\right) h_{a}^{\prime}}{\left(h_{s}-h_{a}^{\prime}\right)^{2}}$

$\frac{\partial h_{s}}{\partial h}=\frac{g h_{s}}{R T_{s}}(\mathrm{C} .17)$

$9 \quad \frac{\partial h}{\partial \theta}=\frac{h_{g}}{m n \theta_{s}}\left(\frac{\theta}{\theta_{s}}\right)^{\left(-\frac{1}{m}-1\right)}\left[\left(\frac{\theta}{\theta_{s}}\right)^{-\frac{1}{m}}-1\right]^{\left(\frac{1}{n}-1\right)}$ (C.18) with $h=h_{g}\left[\left(\frac{\theta}{\theta_{s}}\right)^{-\frac{1}{m}}-1\right]^{\frac{1}{n}^{\frac{1}{n}}}$

$10 \quad \frac{\partial R_{i E}^{v}}{\partial \delta_{i s}^{l}}=\frac{\partial R_{i E}^{v}}{\partial R_{i s}^{l}} \frac{\partial R_{i s}^{l}}{\partial \delta_{i s}^{l}}=\frac{1}{\alpha_{K}} \frac{\alpha_{e}^{*} h_{s}}{\left(h_{s}-h_{a}^{\prime}\right)} \frac{R_{r e f}}{1000}$

$11 \quad \frac{\partial R_{i E}^{v}}{\partial \delta_{i a}^{v}}=\frac{\partial R_{i E}^{v}}{\partial R_{i a}^{v}} \frac{\partial R_{i a}^{v}}{\partial \delta_{i a}^{v}}=-\frac{1}{\alpha_{K}} \frac{h_{a}^{\prime}}{\left(h_{s}-h_{a}^{\prime}\right)} \frac{R_{r e f}}{1000}$

12 where $R_{\text {ref }}$ are the reference values for the isotopic ratio $\left(2005.210^{-6}\right.$ for $\left.\mathrm{H}_{2}{ }^{18} \mathrm{O}\right)$

$13 \quad \frac{\partial R_{i E}^{v}}{\partial \alpha_{K}}=-\frac{R_{i E}^{v}}{\alpha_{K}}$

14 We also estimated the standard error using a more empirical method by deriving a series of

15 estimation of the water vapor isotopic composition and by combining all the possibilities with 
$1+$ or - standard errors on all the variables (64 combinations with 6 variables) using Eq. (C.23).

2

$$
\begin{aligned}
\Delta R_{i E}^{v} & =\left(\frac{\partial R_{i E}^{v}}{\partial T_{s}}\right)_{T_{s}}\left( \pm \Delta T_{s}\right)+\left(\frac{\partial R_{i E}^{v}}{\partial T_{a}}\right)_{T_{a}}\left( \pm \Delta T_{a}\right)+\left(\frac{\partial R_{i E}^{v}}{\partial h_{a}}\right)_{h_{a}}\left( \pm \Delta h_{a}\right)+\left(\frac{\partial R_{i E}^{v}}{\partial \delta_{i s}^{l}}\right)_{\delta_{i s}^{l}}\left( \pm \Delta \delta_{i s}^{l}\right)+ \\
& +\left(\frac{\partial R_{i E}^{v}}{\partial \delta_{i a}^{v}}\right)_{\delta_{i a}^{v}}\left( \pm \Delta \delta_{i a}^{v}\right)+\left(\frac{\partial R_{i E}^{v}}{\partial \theta}\right)_{\theta}( \pm \Delta \theta)
\end{aligned}
$$

3 We checked that the standard deviation of the corresponding series was equal to the standard

4 error given by Eq. (C.2 in Appendix C). With this method we were able to get minimum and

5 maximum values for the estimation of the composition of the soil evaporation and to know which combinations of errors were leading to values closer to the observations.

Appendix D: Derivation of standard error for the estimated isotopic composition of the soil

9 liquid water which matches the observed isotopic composition of the evaporated water vapor.

$$
R_{i s}^{l}=\frac{R_{\text {iout }}^{v}\left(h_{s} \alpha_{K}-h_{a}^{\prime}\left(\alpha_{K}-1\right)\right)}{\alpha_{e}^{*} h_{s}}
$$

The standard error can be obtained using an extension of the formula proposed by Phillips and $\sigma_{R_{i s}^{l}}$ can be obtained as:

$$
\sigma_{R_{i s}^{l}}^{2}=\left(\frac{\partial R_{i s}^{l}}{\partial T_{s}}\right)^{2} \sigma_{T_{s}}^{2}+\left(\frac{\partial R_{i s}^{l}}{\partial T_{a}}\right)^{2} \sigma_{T_{a}}^{2}+\left(\frac{\partial R_{i s}^{l}}{\partial h_{a}}\right)^{2} \sigma_{h a}^{2}+\left(\frac{\partial R_{i s}^{l}}{\partial \delta_{i o u t}^{v}}\right)^{2} \sigma_{\delta_{\text {iout }}^{v}}^{2}+\left(\frac{\partial R_{i s}^{l}}{\partial \theta}\right)^{2} \sigma_{\theta}^{2}+\left(\frac{\partial R_{i s}^{l}}{\partial \alpha_{K}}\right)^{2} \sigma_{\alpha_{K}}^{2}
$$

$$
\text { The partial derivatives of Eq. (D.2.) can be obtained using the chain rules: }
$$


$1 \quad \frac{\partial R_{i s}^{l}}{\partial T_{s}}=\frac{\partial \alpha_{K}}{\partial \alpha_{e}^{*}} \frac{\partial \alpha_{e}^{*}}{\partial T_{s}}+\frac{\partial R_{i s}^{l}}{\partial h_{a}^{\prime}} \frac{\partial h_{a}^{\prime}}{\partial T_{s}}$

2

$$
\frac{\partial R_{i s}^{l}}{\partial h_{a}}=\frac{\partial R_{i s}^{l}}{\partial h_{a}^{\prime}} \frac{\partial h_{a}^{\prime}}{\partial h_{a}}
$$

3

$$
\frac{\partial R_{i s}^{l}}{\partial \theta}=\frac{\partial R_{i s}^{l}}{\partial h_{s}} \frac{\partial h_{s}}{\partial h} \frac{\partial h}{\partial \theta}(\mathrm{D} .7)
$$

$$
\frac{\partial R_{i s}^{l}}{\partial T_{a}}=\frac{\partial R_{i s}^{l}}{\partial h_{a}^{\prime}} \frac{\partial h_{a}^{\prime}}{\partial T_{a}}(\mathrm{D} .4)
$$$$
\frac{\partial R_{i s}^{l}}{\partial \delta_{\text {iout }}^{v}}=\frac{\partial R_{\text {is }}^{l}}{\partial R_{\text {iout }}^{v}} \frac{\partial R_{\text {iout }}^{v}}{\partial \delta_{\text {iout }}^{v}}(\mathrm{D} .6)
$$$$
\frac{\partial R_{i s}^{l}}{\partial \alpha_{K}}=\frac{R_{\text {iout }}^{v}\left(h_{s}-h_{a}^{\prime}\right)}{\alpha_{e}^{*} h_{s}}(\mathrm{D} .8)
$$

4 The partial derivatives appearing in these expressions, not already provided in Appendix C,

5 are given below:

6

$7 \quad \frac{\partial R_{i s}^{l}}{\partial h_{a}^{\prime}}=-\frac{R_{\text {iout }}^{v}\left(\alpha_{K}-1\right)}{\alpha_{e}^{*} h_{s}}$

$$
\frac{\partial R_{i s}^{l}}{\partial \delta_{\text {iout }}^{v}}=\frac{\partial R_{i s}^{l}}{\partial R_{\text {iout }}^{v}} \frac{\partial R_{\text {iout }}^{v}}{\partial \delta_{\text {ia }}^{v}}=\frac{\left(h_{s} \alpha_{K}-h_{a}^{\prime}\left(\alpha_{K}-1\right)\right)}{\alpha_{e}^{*} h_{s}} \frac{R_{\text {ref }}}{1000}
$$$$
\frac{\partial R_{i s}^{l}}{\partial h_{s}}=\frac{R_{\text {iout }}^{v} h_{a}^{\prime}\left(\alpha_{K}-1\right)}{\alpha_{e}^{*} h_{s}^{2}}
$$

9 As in Appendix C, we also derived an empirical estimation of the error using the following

equation:

$$
\begin{aligned}
\Delta R_{i s}^{l} & =\left(\frac{\partial R_{i s}^{l}}{\partial T_{s}}\right)_{T_{s}}\left( \pm \Delta T_{s}\right)+\left(\frac{\partial R_{i s}^{l}}{\partial T_{a}}\right)_{T_{a}}\left( \pm \Delta T_{a}\right)+\left(\frac{\partial R_{i s}^{l}}{\partial h_{a}}\right)_{h_{a}}\left( \pm \Delta h_{a}\right)+\left(\frac{\partial R_{i s}^{l}}{\partial \delta_{\text {iout }}^{v}}\right)_{\delta_{\text {iout }}^{v}}\left( \pm \Delta \delta_{\text {iout }}^{v}\right)+ \\
& +\left(\frac{\partial R_{i s}^{l}}{\partial \theta}\right)_{\theta}( \pm \Delta \theta)+\left(\frac{\partial R_{i s}^{l}}{\partial \alpha_{K}}\right)_{\delta_{i s}^{l}}\left( \pm \Delta \alpha_{K}\right)
\end{aligned}
$$

Appendix E: Derivation of standard error for the estimated kinetic fractionation factor using

15 The kinetic fractionation factor is given by Eq. (16)

16

$$
\alpha_{K}=\frac{\left(\alpha_{e}^{*} R_{i s}^{l} h_{s}-R_{\text {iout }}^{v} h_{a}^{\prime}\right)}{\left(h_{s}-h_{a}^{\prime}\right) R_{\text {iout }}^{v}}
$$


1 The standard error can be obtained using an extension of the formula proposed by Phillips and

2 Gregg (2001). The result of Eq. (E.1) depends on errors on the measurements of air

3 temperature and humidity $T_{a}$ and $h_{a}$, the soil temperature $T_{s}$, the soil surface water content $\theta$,

4 the isotopic composition of the soil surface liquid water $\delta_{i s}^{l}$ and of the water vapor above the

5 soil column, equal to that at the outlet of the column $\delta_{\text {iout }}^{v}$. We assume that the errors on all

6 these factors are independent. Thus the standard error $\sigma_{\alpha_{K}}$ can be obtained as:

$7 \quad \sigma_{\alpha_{K}}^{2}=\left(\frac{\partial \alpha_{K}}{\partial T_{s}}\right)^{2} \sigma_{T_{s}}^{2}+\left(\frac{\partial \alpha_{K}}{\partial T_{a}}\right)^{2} \sigma_{T_{a}}^{2}+\left(\frac{\partial \alpha_{K}}{\partial h_{a}}\right)^{2} \sigma_{h a}^{2}+\left(\frac{\partial \alpha_{K}}{\partial \delta_{i s}^{l}}\right)^{2} \sigma_{\delta_{i s}^{l}}^{2}+\left(\frac{\partial \alpha_{K}}{\partial \delta_{\text {iout }}^{v}}\right)^{2} \sigma_{\delta_{\text {iout }}^{v}}^{2}+\left(\frac{\partial \alpha_{K}}{\partial \theta}\right)^{2} \sigma_{\theta}^{2}$

9 The partial derivatives of Eq. (E.2) can be obtained using the chain rules:

10

11

$$
\frac{\partial \alpha_{K}}{\partial T_{s}}=\frac{\partial \alpha_{K}}{\partial \alpha_{e}^{*}} \frac{\partial \alpha_{e}^{*}}{\partial T_{s}}+\frac{\partial \alpha_{K}}{\partial h_{a}^{\prime}} \frac{\partial h_{a}^{\prime}}{\partial T_{s}}(\mathrm{E} .3) \quad \frac{\partial \alpha_{K}}{\partial T_{a}}=\frac{\partial \alpha_{K}}{\partial h_{a}^{\prime}} \frac{\partial h_{a}^{\prime}}{\partial T_{a}}(\mathrm{E} .4)
$$

$$
\frac{\partial \alpha_{K}}{\partial h_{a}}=\frac{\partial \alpha_{K}}{\partial h_{a}^{\prime}} \frac{\partial h_{a}^{\prime}}{\partial h_{a}}
$$

$$
\frac{\partial \alpha_{K}}{\partial \delta_{i s}^{l}}=\frac{\partial \alpha_{K}}{\partial R_{i s}^{l}} \frac{\partial R_{i s}^{l}}{\partial \delta_{i s}^{l}}(\mathrm{E} .6)
$$

12

$$
\frac{\partial \alpha_{K}}{\partial \delta_{\text {iout }}^{v}}=\frac{\partial \alpha_{K}}{\partial R_{\text {iout }}^{v}} \frac{\partial R_{\text {iout }}^{v}}{\partial \delta_{\text {iout }}^{v}}
$$

$$
\frac{\partial \alpha_{K}}{\partial \theta}=\frac{\partial \alpha_{K}}{\partial h_{s}} \frac{\partial h_{s}}{\partial h} \frac{\partial h}{\partial \theta}(\mathrm{E} .8)
$$

The partial derivatives appearing in these expressions, not already provided in Appendix C, are given below:

$$
\frac{\partial \alpha_{K}}{\partial \alpha_{e}^{*}}=\frac{R_{i s}^{l} h_{s}}{R_{\text {iout }}^{v}\left(h_{s}-h_{a}^{\prime}\right)}
$$

$$
\frac{\partial \alpha_{K}}{\partial h_{a}^{\prime}}=\frac{\left(\alpha_{e}^{*} R_{i s}^{l}-R_{\text {iout }}^{v}\right) h_{s}}{R_{\text {iout }}^{v}\left(h_{s}-h_{a}^{\prime}\right)^{2}}
$$

$$
\frac{\partial \alpha_{K}}{\partial h_{s}}=-\frac{\left(\alpha_{e}^{*} R_{i s}^{l}-R_{\text {iout }}^{v}\right) h_{a}^{\prime}}{R_{\text {iout }}^{v}\left(h_{s}-h_{a}^{\prime}\right)^{2}}
$$

$$
\frac{\partial \alpha_{K}}{\partial \delta_{i s}^{l}}=\frac{\partial \alpha_{K}}{\partial R_{i s}^{l}} \frac{\partial R_{i s}^{l}}{\partial \delta_{i s}^{l}}=\frac{\alpha_{e}^{*} h_{s}}{R_{\text {iout }}^{v}\left(h_{s}-h_{a}^{\prime}\right)} \frac{R_{r e f}}{1000}
$$

$$
\frac{\partial \alpha_{K}}{\partial \delta_{\text {iout }}^{v}}=\frac{\partial \alpha_{K}}{\partial R_{\text {iout }}^{v}} \frac{\partial R_{\text {iout }}^{v}}{\partial \delta_{\text {ia }}^{v}}=-\frac{h_{s} \alpha_{e}^{*} R_{\text {is }}^{l}}{\left(R_{\text {iout }}^{v}\right)^{2}\left(h_{s}-h_{a}^{\prime}\right)} \frac{R_{\text {ref }}}{1000}
$$


Paper published in Journal of Hydrology, 369, 1-16, 2009, 10.1016/j.jhydrol.2009.01.034

1 As in Appendix C, we also derived an empirical estimation of the error using the following

2 equation:

3

$$
\begin{aligned}
\Delta \alpha_{K} & =\left(\frac{\partial \alpha_{K}}{\partial T_{s}}\right)_{T_{s}}\left( \pm \Delta T_{s}\right)+\left(\frac{\partial \alpha_{K}}{\partial T_{a}}\right)_{T_{a}}\left( \pm \Delta T_{a}\right)+\left(\frac{\partial \alpha_{K}}{\partial h_{a}}\right)_{h_{a}}\left( \pm \Delta h_{a}\right)+\left(\frac{\partial \alpha_{K}}{\partial \delta_{i s}^{l}}\right)_{\delta_{i s}^{l}}\left( \pm \Delta \delta_{i s}^{l}\right)+ \\
& +\left(\frac{\partial \alpha_{K}}{\partial \delta_{\text {iout }}^{v}}\right)_{\delta_{\text {iout }}^{v}}\left( \pm \Delta \delta_{\text {iout }}^{v}\right)+\left(\frac{\partial \alpha_{K}}{\partial \theta}\right)_{\theta}( \pm \Delta \theta)
\end{aligned}
$$

4

5 


\section{References}

2 Araguás-Araguás, L., Rozanski, K., Gonfiantini, R., Louvat, D., 1995. Isotope effects

3 accompanying vacuum extraction of soil water for stable isotope analyses. J.Hydrol. 168, $4 \quad 159-171$.

5 Bariac, T., Gonzalez-Dunia, J., Katerji, N., Béthenod, O., Bertolini, J.M., Mariotti, A., 1994.

6 Variabilité spatio-temporelle de la composition isotopique de l'eau $(18 \mathrm{O}, 2 \mathrm{H})$ dans le 7 continuum sol-plante-atmosphère : 2. Approche en conditions naturelles. Chem. Geol. 115(38 4), 317-333.

9 Barnes, C.J., Allison, G.B., 1983. The distribution of deuterium and 180 in dry soils: 1. Theory. J. Hydrol. 60, 141-156.

11 Barnes, C.J., Allison, G.B., 1984. The distribution of D and 180 in dry soils. 3- Theory for 12 non-isothermal water movement. J. Hydrol. 74, 119-135.

Braud, I., Bariac, T., Biron, Ph., Vauclin, M., 2009. Isotopic composition of bare soil evaporated water vapor. Part II: Modelling of RUBIC IV experimental results. J. Hydrol., submitted.

Braud, I., Bariac, T., Gaudet, J.P., Vauclin, M., 2005a. SiSPAT-Isotope , a coupled heat, water and stable isotope (HDO and H218O) transport model for bare soil. Model description and first verification. J. Hydrol. 309(1-4), 277-300.

Braud, I., Bariac, T., Vauclin, M., Boujamlaoui, Z., Gaudet, J.P., Biron, P., Richard, P., 2005b. SiSPAT-Isotope, a coupled heat, water and stable isotope (HDO and H218O)

21 transport model for bare soil. Evaluation and sensitivity tests using two laboratory data sets. J.

22 Hydrol. 309(1-4), 301-320.

23 Cappa, C.D., Hendricks, M.B., DePaolo, D.J., Cohen, R.C., 2003. Isotopic fractionation of 24 water during evaporation. J. Geophys. Res. 108(D16), 4525, doi:10.1029/2003JD003597. 
1 Chahine, M. T. (1992). The hydrological cycle and its influence on climate. Nature 359, 3732380.

3 Costanza, R. et al.. 1997. The value of the world's ecosytems services and natural capital.

$4 \quad$ Nature 387, 253-260.

5 Craig, H., Gordon, L.I., 1965. Deuterium and oxygen 18 variations in the ocean and the

6 marine atmosphere, Proceedings of the Conference on the stable isotopes in oceanographic

7 studies and paleotemperatures, Lab. Geol. Nucl., Pisa, Italy, 9-130.

8 Dongmann, G., Nürnberg, H.W., 1974. On the enrichment of H218O in the leaves of

9 transpiring plants. Rad. and Environm. Biophys. 11, 41-52.

10 Gonfiantini, R., 1978. Standards for stable isotope measurements in natural compounds.

$11 \quad$ Nature 271, 534-536.

12 Majoube, M.A., 1971. Fractionnement en oxygène-18 et en deutérium entre l'eau et sa 13 vapeur, J. Chem. Phys. 68, 1423-1436.

14 Merlivat, L., 1978. Molecular diffusivity of H216O, HD16O and H218O in gases. J. Chem.

15 Physics 69(6), 2864-2871.

16 Merlivat, L., Jouzel, J., 1979. Global climatic interpretation of the Deuterium-Oxygen 18

17 relationship for precipitation. J. Geophys. Res. 84(C8), 5029-5033.

18 Parlange M.B., Katul G.G., 1992, Estimation of the diurnal variation of potential evaporation

19 from a wet bare soil surface, J. Hydrol. 132, 71-89.

20 Phillips, D.L., Gregg, J.W., 2001. Uncertainty in source partitioning using stable isotopes.

21 Oecologia 127, 171-179.

22 Schoch-Fischer H., Rozanski K., Jacob H., Sonntag C., Jouzel J., Ostlund G., Geyh M.A..

23 1983. Hydrometeorological factors controlling the time variation of $\mathrm{D},{ }^{18} \mathrm{O}$ and ${ }^{3} \mathrm{H}$ in

24 atmospheric water vapour and precipitation in the northwestern westwind belt. In Proc. Symp.

25 Vienna, 12-16 september 1983, AIEA-UNESCO, Isotope Hydrology: Vienna; 3-30. 
1 Van Genuchten, M.T., 1980. A closed-form equation for predicting the hydraulic conductivity

2 of unsaturated soils. Soil Sci. Soc.Am. J. 44, 892-898.

3 Walker, C.D., Richardson, S.B., 1991. The use of stable isotopes of water in characterizing

4 the sources of water in vegetation. Chem. Geol. (Iso. Geo. Sect.) 94, 145-158.

5 Williams, D.G., Cable, W., Hultine, K., Hoedjes, J.C.B., Yepez, E.A., Simmoneaux, V., Er-

6 Raki, S., Boulet, G., de Bruin, H.A.R., Cheehbouni, A., Hartogensis, O.K., Timouk, F., 2004.

7 Evapotranspiration components determined by stable isotope, sap flow and eddy covariance

8 techniques. Agricul. For. Meteorol. 125, 241-258.

9 Yakir, D., da Silveira Lobo Sternberg, L., 2000. The use of stable isotopes to study ecosystem 10 gas exchange. Oecologia 123, 297-311.

11 Yepez, E.A., Williams, D.G., Scott, R.L., Lin, G., 2003. Partitioning overstory and understory

12 evapotranspiration in a semiarid savanna woodland from the isotopic composition of water 13 vapor. Agricul. For. Meteorol. 119(1-2), 53-68.

14 Zangvil, A., Portis, D.H., Lamb, P.J., 2004. Investigation of the large scale atmospheric

15 moisture field over the Midwestern United States in relation to summer precipitation. Part II:

16 Recycling of local evapotranspiration and association with soil moisture and crop yields. J.

17 Climate 17, 3283-3301.

18 Zimmermann U., Ehhalt D., Münnich K.O., 1967. Soil - water movement and

19 evapotranspiration: changes in the isotopic composition of the water. Proc. Symp. Isot.

20 Hydrol., Vienna, I. A. E. A., pp 567-584. 


\section{$1 \quad$ List of figures}

2 Figure 1. Photo of the experimental set up.

3 Figure 2. Scheme of the experimental set up (view from the top).

4 Figure 3: Time evolution of air temperature and relative humidity at the outlet of column 1.

5 Figure 4. Evolution of the oxygen 18 composition of the liquid water as function of the

6 gravimetric water content $\left(\mathrm{kg} \mathrm{kg}^{-1}\right)$. The results were obtained after $15 \mathrm{~h}$ of distillation and

7 corrected for the efficiency of the extraction. The target initial oxygen 18 isotopic

8 composition of the liquid water is $-7.10 \pm 0.05 \%$. Vertical bars correspond to the analytical

$9 \operatorname{errors}( \pm 0.1 \%)$.

10 Figure 5. Retention curve $h(\theta)$ of the soil. The squares correspond to the measured $(h, \theta)$

11 couples at $-2.5 \mathrm{~cm}$ (full square), $-8 \mathrm{~cm}$ (crosses), $-16 \mathrm{~cm}$ (open triangles). The continuous line

12 corresponds to the fitted Van Genuchten model $\frac{\theta}{\theta_{\mathrm{sat}}}=\left(1+\left(\frac{h}{h_{\mathrm{VG}}}\right)^{n}\right)^{-m}$ with $m=1-\frac{2}{n}$ for

13 the $-2.5 \mathrm{~cm}$ data. Values of the parameters are $n=2.36, h_{V G}=-1.05 \mathrm{~m}, \theta_{\text {sat }}=0.444$.

14 Figure 6. Comparison of the cumulative evaporation (left) and the instantaneous flux (right)

15 estimated by using the measures of air flow and water vapor humidity at the outlet (full

16 black), the weighting of the columns (dashed black), the trapped water volume at the outlet

17 (dashed light) and the calculated soil water storage (full light) for column 1 (top) and column

184 (bottom).

19 Figure 7. Evaporation flux of the six columns (top) and cumulative evaporation of the six

20 columns (bottom). Values were calculated using Method 1.

21 Figure 8. Volumetric water content (left) and oxygen 18 isotopic ratio (right) (in $\%$ ) of the

22 six soil columns when they were dismantled. The vertical straight lines are the initial values.

23 DoY is Day of the Year 
1 Figure 9. Time evolution of the oxygen 18 isotopic ratio of the evaporated water vapor for the

2 six columns. The horizontal black line gives the composition of the initial water $-6.4 \%$. The

3 sampling frequency is twice a day from DoY 101 to 136; once a day from DoY 137 to 224

4 and then about one sample every two or three days.

5 Figure 10. Comparison of the measured oxygen 18 composition of the evaporated water vapor

6 (squares) and the calculated one using Eq. (6) with $\alpha_{K}=1.0189$ (points). Values of the

7 standard error, as well as their minimum and maximum, estimated using analytical and sensor

8 accuracy errors are also plotted. Results with soil water content and liquid isotopic ratios

9 sampled over the $0-2.5 \mathrm{~cm}$ and $0-0.5$ or $0-1 \mathrm{~cm}$ layers are represented in the top and bottom

10 panels, respectively.

11 Figure 11. Comparison of the measured oxygen 18 composition of the evaporated water

12 vapour (squares) and the calculated one using Eq. (6) with $\alpha_{K}=1.0189$ (points). Values of the

13 standard error, as well as their minimum and maximum, estimated using sampling errors are

14 plotted. Results with soil water content and liquid isotopic ratios sampled over the $0-2.5 \mathrm{~cm}$

15 and $0-0.5$ or $0-1 \mathrm{~cm}$ layers are represented in the top and bottom panels, respectively.

16 Figure 12. Contribution of the various sources of errors on the calculated isotopic composition

17 of the evaporated water vapor for oxygen 18 for the sampling errors and $\alpha_{K}=1.0189$. Top

18 panel: when error on $\alpha_{K}$ is not taken into account. Bottom panel: when error on $\alpha_{K}$ is taken

19 into account. The dates in abscissa correspond to the lines in Table 6 in the same order. In the

20 legend, the labels refer to errors on soil temperature $T_{s}(\mathrm{Ts})$, isotopic composition of the soil

21 surface liquid water $\delta_{i s}^{l}$ (deltal), water vapor above the soil column $\delta_{i a}^{v}$ (deltair), air

22 temperature $T_{a}(\mathrm{Ta})$, air relative humidity $h_{a}$ (ha), soil water content $\theta$ (theta) and kinetic

23 fractionation factor $\alpha_{K}$ (alphak). 
1 Figure 13. Value of the isotopic composition of the soil liquid water, required so that the

2 isotopic composition of the evaporated water vapor calculated using Eq. (6) matches the

3 measured value. The standard error, minimum and maximum values estimated using sampling

4 errors are also plotted. Measured values correspond to the $0-2.5 \mathrm{~cm}$ depth layer.

5 Figure 14 Contribution of the various sources of errors on the calculated isotopic composition

6 of the soil liquid water required so that the isotopic composition of the evaporated water

7 vapor calculated using Eq. (6) matches the measured value calculated using oxygen 18 and

8 the sampling errors. Top: error on the kinetic fractionation factor is not considered. Bottom:

9 Error on the kinetic fractionation factor is considered. The dates in abscissa correspond to the

10 lines in Table 8 in the same order. In the legend the labels refer to errors on soil temperature

$11 T_{s}(\mathrm{Ts})$, water vapor above the soil column $\delta_{i a}^{v}$ (deltair), air temperature $T_{a}(\mathrm{Ta})$, air relative

12 humidity $h_{a}$ (ha), soil water content $\theta$ (theta) and kinetic fractionation factor $\alpha_{K}$ (alphak).

13 Figure 15. Contribution of the various sources of errors on the calculated kinetic fractionation

14 factor for oxygen 18 and for the sampling errors. The dates in abscissa correspond to the lines

15 in Table 9 in the same order. In the legend the labels refer to errors on soil temperature $T_{s}$

16 (Ts), isotopic composition of the soil surface liquid water $\delta_{i s}^{l}$ (deltal), water vapor above the

17 soil column $\delta_{i a}^{v}$ (deltair), air temperature $T_{a}(\mathrm{Ta})$, air relative humidity $h_{a}($ ha), soil water

18 content $\theta$ (theta). 
1 Table 1 Dates and values at which the constraint on the relative humidity above the soil

2 column was modified

\begin{tabular}{llll}
\hline $\begin{array}{l}\text { Date of change of the } \\
\text { prescribed relative } \\
\text { humidity }\end{array}$ & $\begin{array}{l}\text { Corresponding Day } \\
\text { of the Year }\end{array}$ & $\begin{array}{l}\text { Time since } \\
\text { beginning of } \\
\text { simulation (s) }\end{array}$ & $\begin{array}{l}\text { Value of the } \\
\text { prescribed relative } \\
\text { humidity (-) }\end{array}$ \\
\hline $\begin{array}{l}\text { April 11 2005 12h00 } \\
\text { July 25 2005 16h45 }\end{array}$ & DoY 101 12h00 & 0 & 0.8 \\
August 28 2005 15h00 & DoY 241 15h00 & $1.2106810^{7}$ & 0.6 \\
$\begin{array}{l}\text { September 26 2005 12h45 } \\
\text { October 14 2005 16h15 }\end{array}$ & DoY 269 287 16h15 & $1.6085710^{7}$ & 0.3 \\
November 2 2005 12h00 & DoY 306 12h00 & $1.771210^{7}$ & 0.2 \\
\hline
\end{tabular}


1 Table 2 Initial weight, moisture and isotopic conditions of the six columns

\begin{tabular}{|c|c|c|c|c|c|c|}
\hline & Column & Column & Column & Column & Column & Column \\
\hline & 6 & 5 & 3 & 2 & 4 & 1 \\
\hline Soil Volume $\left(\mathrm{cm}^{3}\right)$ & 3958 & 3958 & 3958 & 3958 & 3958 & 3971 \\
\hline Dry soil mass (g) & 5603 & 5698 & 5456 & 5470 & 5580 & 5661 \\
\hline \multicolumn{7}{|l|}{ Water mass for the saturation of the } \\
\hline soil (g) & 1678 & 1742 & 1724 & 1717 & 1691 & 1728 \\
\hline Saturated water content ${ }^{(\mathrm{a})}\left(\mathrm{m}^{3} \mathrm{~m}^{-3}\right)$ & 0.42 & 0.44 & 0.44 & 0.43 & 0.43 & 0.44 \\
\hline Dry bulk density $^{(\mathrm{b})}\left(\mathrm{g} \mathrm{cm}^{-3}\right)$ & 1.42 & 1.44 & 1.38 & 1.38 & 1.41 & 1.44 \\
\hline \multicolumn{7}{|l|}{ Isotopic concentration in $\mathrm{H}_{2}{ }^{18} \mathrm{O}$ of } \\
\hline the initial water at the surface $(\%)$ & -6.5 & -6.4 & -6.5 & -6.6 & -6.3 & -6.5 \\
\hline \multicolumn{7}{|l|}{ Isotopic concentration in $\mathrm{H}_{2}{ }^{18} \mathrm{O}$ of } \\
\hline the initial water at $-0.35 \mathrm{~m}(\% \circ)$ & -6.5 & -5.5 & -6.4 & -6.3 & -5.8 & -6.4 \\
\hline
\end{tabular}

$2{ }^{\text {(a) }}$ Calculated as the water volume divided by the soil volume

3 (b) Calculated as the ratio of the soil mass to the soil volume 
Paper published in Journal of Hydrology, 369, 1-16, 2009, 10.1016/j.jhydrol.2009.01.034

1 Table 3 Dates at which the columns were dismantled. The experiment was launched on April

$2 \quad 112005$ at $12 \mathrm{~h} 00$ (DoY 101)

\begin{tabular}{llll}
\hline $\begin{array}{l}\text { Column } \\
\text { number }\end{array}$ & $\begin{array}{l}\text { Date of dismantling } \\
\text { of the columns }\end{array}$ & $\begin{array}{l}\text { Date of Year } \\
\text { (DoY) }\end{array}$ & $\begin{array}{l}\text { Number of days after } \\
\text { beginning of drying }\end{array}$ \\
\hline 6 & May 12 2005 & 132 & 31 \\
5 & June 3 2005 & 154 & 53 \\
3 & July 11 2005 & 192 & 91 \\
2 & September 21 2005 & 264 & 163 \\
4 & December 2 2005 & 336 & 235 \\
1 & March 15 2006 & $439(74+365)$ & 338 \\
\hline
\end{tabular}

3 
Table 4 Data used for the estimation of the isotopic composition of the evaporated water vapor and the kinetic fractionation factor. Lines in grey correspond to the same dates but the soil water content and isotopic ratio were sampled over different depths: $0-2.5 \mathrm{~cm}$ in the top panel and $0-0.5$ or $0-0.1 \mathrm{~cm}$ in the bottom panel.
Decimal Day $\quad \mathrm{T}_{\text {air }}\left({ }^{\circ} \mathrm{C}\right)$
$\mathrm{h}_{\mathrm{u} \_ \text {air }}(-)$
$\mathrm{T}_{\text {soil }} \quad$ at Volumetric water $\delta_{\text {is }}^{1} \mathrm{H}_{2}{ }^{18} \mathrm{O}$
$\delta^{\mathrm{v}}{ }_{\mathrm{ia}} \mathrm{H}_{2}{ }^{18} \mathrm{O}$
Soil surface
Soil surface
Normalized
of the Year
$-2.5 \mathrm{~cm}\left({ }^{\circ} \mathrm{C}\right)$ content $\left(\mathrm{m}^{3} \mathrm{~m}^{-3}\right) \quad(\%)$
$(\%)$
water pressure relative
air relative
(m) humidity $\mathrm{h}_{\mathrm{s}}(-)$ humidity $\mathrm{h}_{\mathrm{a}}{ }^{\prime}(-)$

Soil water content and isotopic ratio values averaged over $\mathbf{0 - 2 . 5} \mathbf{~ c m}$

\begin{tabular}{|c|c|c|c|c|c|c|c|c|c|}
\hline & & & & & & & & & \\
\hline 101.50 & 24.48 & 0.77 & 24.6 & 0.44 & -6.5 & -17.0 & -0.3 & 1.000 & 0.77 \\
\hline 132.46 & 22.02 & 0.80 & 22.5 & 0.34 & 0.7 & -7.4 & -2.1 & 1.000 & 0.77 \\
\hline 145.41 & 21.46 & 0.80 & 21.5 & 0.31 & 4.4 & -5.3 & -2.7 & 1.000 & 0.77 \\
\hline 154.43 & 24.87 & 0.80 & 24.7 & 0.26 & 5.1 & -4.1 & -4.5 & 1.000 & 0.75 \\
\hline 171.65 & 21.00 & 0.80 & 21.3 & 0.20 & 5.5 & -3.9 & -9.4 & 0.999 & 0.87 \\
\hline 181.58 & 21.25 & 0.80 & 21.6 & 0.15 & 4.7 & -3.3 & -20.0 & 0.999 & 0.90 \\
\hline 192.53 & 22.75 & 0.80 & 22.7 & 0.13 & 1.4 & -5.4 & -34.3 & 0.998 & 0.79 \\
\hline 231.77 & 22.60 & 0.60 & 22.7 & 0.07 & 2.3 & -9.7 & -185.0 & 0.987 & 0.59 \\
\hline 252.42 & 21.42 & 0.50 & 22.2 & 0.05 & 4.6 & -9.4 & -347.5 & 0.975 & 0.47 \\
\hline 264.55 & 20.42 & 0.50 & 20.6 & 0.05 & 2.8 & -10.2 & -514.4 & 0.963 & 0.50 \\
\hline 287.65 & 22.00 & 0.40 & 22.6 & 0.04 & 1.9 & -10.6 & -720.1 & 0.950 & 0.39 \\
\hline 336.58 & 22.60 & 0.20 & 22.9 & 0.03 & 5.6 & -12.0 & -1929.3 & 0.871 & 0.20 \\
\hline 439.58 & 21.97 & 0.20 & 22.9 & 0.02 & 0.8 & -13.1 & -4358.3 & 0.731 & 0.19 \\
\hline \multicolumn{10}{|c|}{ Soil water content and isotopic ratio averaged over $0-0.5$ or $0-1 \mathrm{~cm}$} \\
\hline 336.58 & 22.60 & 0.20 & 22.9 & 0.03 & 1.5 & -12.0 & -2156.7 & 0.857 & 0.20 \\
\hline 439.58 & 21.97 & 0.20 & 22.9 & 0.02 & -0.1 & -13.1 & -3912.5 & 0.755 & 0.19 \\
\hline
\end{tabular}


Paper published in Journal of Hydrology, 369, 1-16, 2009, 10.1016/j.jhydrol.2009.01.034

1 Table 5 Values of the cumulative evaporation $(\mathrm{mm})$ for the six columns estimated by four

2 methods

\begin{tabular}{|c|c|c|c|c|c|c|}
\hline Method & $\begin{array}{l}\text { Column } \\
6\end{array}$ & $\begin{array}{l}\text { Column } \\
5\end{array}$ & $\begin{array}{l}\text { Column } \\
3\end{array}$ & $\begin{array}{l}\text { Column } \\
2\end{array}$ & $\begin{array}{l}\text { Column } \\
4\end{array}$ & $\begin{array}{l}\text { Column } \\
1\end{array}$ \\
\hline $\begin{array}{l}\text { Method 1: measures of air } \\
\text { flow and humidity }\end{array}$ & 35.3 & 58.4 & 77.2 & 105.1 & 113.3 & 130.2 \\
\hline $\begin{array}{l}\text { Method 2: weighting of the } \\
\text { columns }\end{array}$ & 36.8 & 58.3 & 79.5 & 102.6 & 108.7 & 133.1 \\
\hline Method 3: trapped volumes & 37.2 & 57.8 & 80.5 & 102.9 & 112.3 & 132.5 \\
\hline $\begin{array}{l}\text { Method 4: soil water storage } \\
\text { variation }\end{array}$ & - & - & - & - & - & 120.8 \\
\hline
\end{tabular}

3

4 
1 Table 6 Comparison between the measured isotopic composition of the evaporated water

2 vapor and the use of Eq. (6) with different values of the kinetic fractionation factor:1.014

3 (turbulent transport), 1.0189 (laminar transport) and 1.0285 (molecular transport). Lines in

4 grey correspond to the same dates but the soil water content and isotopic ratio were sampled

5 over different depths: $0-2.5 \mathrm{~cm}$ in the top panel and $0-0.5$ or $0-0.1 \mathrm{~cm}$ in the bottom panel.

\begin{tabular}{lllll}
\hline Day of the & Measured $\delta^{\mathrm{v}}{ }_{\mathrm{iE}}$ & Calculated $\delta^{\mathrm{v}}{ }_{\mathrm{iE}}$ & Calculated $\delta^{\mathrm{v}}{ }_{\mathrm{iE}}$ & Calculated $\delta^{\mathrm{v}}{ }_{\mathrm{iE}}$ \\
Year (DoY) & $\mathrm{H}_{2}{ }^{18} \mathrm{O}$ & $\mathrm{H}_{2}{ }^{18} \mathrm{O}$ with & $\mathrm{H}_{2}{ }^{18} \mathrm{O}$ with & $\mathrm{H}_{2}{ }^{8} \mathrm{O}$ with \\
& & $\alpha_{\mathrm{K}}=1.014$ & $\alpha_{\mathrm{K}}=1.0189$ & $\alpha_{\mathrm{K}}=1.0285$
\end{tabular}

\section{Calculation with soil values averaged over $0-2.5 \mathrm{~cm}$}

\begin{tabular}{lllll}
101.50 & -17.0 & -25.1 & -29.7 & -38.8 \\
132.46 & -7.4 & -27.1 & -31.8 & -40.8 \\
138.63 & -6.2 & -21.1 & -25.8 & -34.9 \\
145.41 & -5.3 & -18.4 & -23.1 & -32.2 \\
154.43 & -4.1 & -18.8 & -23.5 & -32.6 \\
164.58 & -3.5 & -15.5 & -20.2 & -29.4 \\
171.65 & -3.9 & -18.7 & -23.5 & -32.6 \\
181.58 & -3.3 & -24.5 & -29.2 & -38.3 \\
\hline 192.53 & -5.4 & -32.5 & -37.2 & -46.2 \\
220.74 & -9.1 & -16.1 & -20.9 & -30.0 \\
231.77 & -9.7 & -17.1 & -21.9 & -31.0 \\
252.42 & -9.4 & -14.6 & -19.3 & -28.5 \\
\hline 264.55 & -10.2 & -17.1 & -21.9 & -31.0 \\
287.65 & -10.6 & -19.3 & -24.0 & -33.1 \\
\hline 336.58 & -12.0 & -15.4 & -20.1 & -29.2 \\
439.58 & -13.1 & -20.8 & -25.5 & -34.6 \\
\hline
\end{tabular}

Calculation with soil values averaged over $0-0.5$ or $\mathbf{0 - 1}$ cm

\begin{tabular}{lllll}
132.46 & -7.4 & -21.1 & -25.8 & -34.9 \\
154.43 & -4.1 & -6.9 & -11.7 & -20.9 \\
192.53 & -5.4 & -25.3 & -29.9 & -39.0 \\
264.55 & -10.2 & -21.6 & -26.3 & -35.4 \\
336.58 & -12.0 & -20.5 & -25.2 & -34.3 \\
439.58 & -13.1 & -22.0 & -26.8 & -35.8 \\
\hline
\end{tabular}


1 Table 7 Values of the error retained for the calculation of the error bars on the composition of

2 evaporated water vapor or the derivation of the kinetic fractionation factors. Two cases are

3 considered. Case 1: Analytical and sensor accuracy only. Case 2: Sampling errors

\begin{tabular}{|c|c|c|c|}
\hline Variable & $\begin{array}{l}\text { Analytical and } \\
\text { sensor } \\
\text { accuracy errors }\end{array}$ & Sampling errors & $\begin{array}{l}\text { Comments on the choice of the values for } \\
\text { the sampling errors }\end{array}$ \\
\hline $\begin{array}{l}\text { Soil and air } \\
\text { temperature } \\
T_{s} \text { and } T_{a}\end{array}$ & $\begin{array}{l}\Delta T_{s}=\Delta T_{a}= \\
0.2^{\circ} \mathrm{C}\end{array}$ & $\Delta T_{s}=\Delta T_{a}=2{ }^{\circ} \mathrm{C}$ & $\begin{array}{l}\text { Takes into account possible difference } \\
\text { between the soil surface and the depth at } \\
\text { which the measured is taken for soil } \\
\text { temperature and possible heterogeneity } \\
\text { above the soil column for air temperature }\end{array}$ \\
\hline $\begin{array}{l}\text { Air relative } \\
\text { humidity } h_{a}\end{array}$ & $\Delta h_{a}=0.01$ & $\Delta h_{a}=0.1$ & $\begin{array}{l}\text { Takes into account possible heterogeneity } \\
\text { of relative humidity above the soil column }\end{array}$ \\
\hline $\begin{array}{l}\text { Soil water } \\
\text { content } \theta\end{array}$ & $\begin{array}{l}\Delta \theta=0.01 \mathrm{~m}^{3} \\
\mathrm{~m}^{-3}\end{array}$ & $\Delta \theta=0.02 \mathrm{~m}^{3} \mathrm{~m}^{-3}$ & $\begin{array}{l}\text { Takes into account possible difference in } \\
\text { the thickness of the soil used to estimate } \\
\text { the soil surface water content and } \\
\text { inaccuracy in the estimation of the } \\
\text { retention curve }\end{array}$ \\
\hline $\begin{array}{l}\text { Water vapor } \\
\text { isotopic } \\
\text { composition }\end{array}$ & $\Delta \delta_{\text {O18out }}^{v}=0.5$ & $\Delta \delta_{\text {O18out }}^{v}=1.25$ & $\begin{array}{l}\text { Estimation based on differences between } \\
\text { the values of different columns (see Fig. 9) }\end{array}$ \\
\hline $\begin{array}{l}\delta_{i o u t}^{v} \\
\text { Soil } \quad \text { surface }\end{array}$ & $\Delta \delta_{O 18 s}^{l}=0.5$ & $\Delta \delta_{O 18 s}^{l}=5$ & $\begin{array}{l}\text { Estimation based on differences between } \\
\text { values averaged over the } 0-2.5 \mathrm{~cm} \text { or } 0-0.5\end{array}$ \\
\hline $\begin{array}{l}\text { liquid } \\
\text { isotopic }\end{array}$ & & & r 0-1 cm depths (see lable 4) \\
\hline composition & & & No difference \\
\hline$\delta_{i s}^{l}$ & $\Delta \alpha_{K O 18}=0.0096$ & $\Delta \alpha_{K O 18}=0.0096$ & \\
\hline $\begin{array}{l}\text { Kinetic } \\
\text { fractionation } \\
\text { factor } \alpha_{K}\end{array}$ & & & \\
\hline
\end{tabular}


Table 8 Estimation of the isotopic composition of the liquid water required to match the measured value of the isotopic composition of the evaporated water vapor with the calculated value using Eq. (6). Standard errors calculated using the formulae of Appendix D are also given when sampling errors are taken into account. Lines in grey correspond to the same dates but the soil water content and isotopic ratio were sampled over different depths: $0-2.5 \mathrm{~cm}$ in the top panel and $0-0.5$ or $0-0.1 \mathrm{~cm}$ in the bottom panel.

\begin{tabular}{|c|c|c|c|c|c|c|c|c|c|c|}
\hline \multirow[b]{2}{*}{$\begin{array}{l}\text { Decimal Day } \\
\text { of the Year } \\
\text { (DoY) }\end{array}$} & \multirow[b]{2}{*}{$\begin{array}{l}\text { Measured at } \\
\text { the surface } \\
\text { (Maximum in } \\
\text { the profile) }\end{array}$} & \multicolumn{3}{|c|}{ Calculation with $\alpha_{K}=1.014$} & \multicolumn{3}{|c|}{ Calculation with $\alpha_{K}=1.0189$} & \multicolumn{3}{|c|}{ Calculation with $\alpha_{K}=1.0285$} \\
\hline & & $\begin{array}{l}\text { Calculated } \\
\text { average }\end{array}$ & $\begin{array}{l}\text { Standard error } \\
\text { without } \alpha_{K}\end{array}$ & $\begin{array}{l}\text { Standard error } \\
\text { with } \alpha_{K}\end{array}$ & $\begin{array}{l}\text { Calculated } \\
\text { average }\end{array}$ & $\begin{array}{l}\text { Standard error } \\
\text { without } \alpha_{K}\end{array}$ & $\begin{array}{l}\text { Standard error } \\
\text { with } \alpha_{K}\end{array}$ & $\begin{array}{l}\text { Calculated } \\
\text { average }\end{array}$ & $\begin{array}{l}\text { Standard error } \\
\text { without } \alpha_{\mathrm{K}}\end{array}$ & $\begin{array}{l}\text { Standard error } \\
\text { with } \alpha_{K}\end{array}$ \\
\hline \multicolumn{11}{|c|}{ Soil values are averaged over the $0-2.5 \mathrm{~cm}$ depth } \\
\hline 101.5 & -6.5 & -4.5 & 2.5 & 3.3 & -3.4 & 3.8 & 4.4 & -1.1 & 4.5 & 5.1 \\
\hline 132.46 & 0.7 & 5.3 & 2.5 & 3.3 & 6.3 & 3.9 & 4.5 & 8.5 & 4.6 & 5.1 \\
\hline 138.63 & 3.3 & 6.4 & 2.6 & 3.3 & 7.4 & 4.0 & 4.4 & 9.4 & 4.8 & 5.2 \\
\hline 145.41 & 4.4 & 7.2 & 2.6 & 3.2 & 8.1 & 4.0 & 4.4 & 10.1 & 4.8 & 5.2 \\
\hline 154.43 & 5.1 & 8.0 & 2.6 & 3.2 & 8.9 & 4.0 & 4.4 & 10.8 & 4.8 & 5.1 \\
\hline 164.58 & 6.7 & 9.5 & 2.6 & 3.3 & 10.5 & 3.9 & 4.5 & 12.6 & 4.7 & 5.2 \\
\hline 171.65 & 5.5 & 8.8 & 2.5 & 3.3 & 9.8 & 3.9 & 4.4 & 11.9 & 4.7 & 5.2 \\
\hline 181.58 & 4.7 & 9.4 & 2.5 & 3.3 & 10.4 & 3.9 & 4.4 & 12.5 & 4.7 & 5.2 \\
\hline 192.53 & 1.4 & 6.9 & 2.6 & 3.2 & 7.9 & 4.0 & 4.4 & 9.8 & 4.8 & 5.1 \\
\hline 220.74 & 3.1 & 6.0 & 2.3 & 4.4 & 7.8 & 3.6 & 5.3 & 9.6 & 4.8 & 5.2 \\
\hline 231.77 & 2.3 & 5.4 & 2.3 & 4.4 & 7.3 & 3.6 & 5.3 & 11.6 & 4.1 & 5.6 \\
\hline 252.42 & 4.6 & 7.3 & 2.1 & 5.3 & 9.8 & 3.5 & 6.0 & 11.1 & 4.1 & 5.6 \\
\hline 264.55 & 2.8 & 6.3 & 2.2 & 5.2 & 8.6 & 3.6 & 5.9 & 14.7 & 3.8 & 6.2 \\
\hline 287.65 & 1.9 & 7.2 & 2.1 & 6.1 & 10.1 & 3.4 & 6.6 & 13.3 & 4.0 & 6.1 \\
\hline 336.58 & 5.6 & 8.4 & 2.2 & 7.7 & 12.0 & 3.5 & 8.2 & 15.8 & 3.7 & 6.8 \\
\hline 439.58 & 0.8 & 6.7 & 3.7 & 8.0 & 10.2 & 5.3 & 8.9 & 19.5 & 3.9 & 8.4 \\
\hline \multicolumn{11}{|c|}{ Soil values are averaged over the $0-0.5$ or $0-1 \mathrm{~cm}$ depth } \\
\hline 132.46 & $2.1(2.1)$ & 5.3 & 2.5 & 3.3 & 6.3 & 3.9 & 4.4 & 17.3 & 7.2 & 10.1 \\
\hline 154.43 & $7.4(7.4)$ & 8.0 & 2.6 & 3.2 & 8.9 & 4.0 & 4.4 & 8.5 & 4.6 & 5.1 \\
\hline 192.53 & $2.9(2.9)$ & 6.9 & 2.6 & 3.2 & 7.8 & 4.0 & 4.4 & 10.8 & 4.8 & 5.1 \\
\hline 264.55 & $0.5(5.1)$ & 6.1 & 2.4 & 5.1 & 8.3 & 3.7 & 5.8 & 9.7 & 4.8 & 5.1 \\
\hline 336.58 & $1.5(11.6)$ & 8.3 & 2.3 & 7.7 & 12.0 & 3.6 & 8.2 & 12.8 & 4.3 & 6.2 \\
\hline 439.58 & $-0.1(11.5)$ & 6.9 & 3.3 & 7.9 & 10.4 & 4.8 & 8.6 & 19.4 & 4.0 & 8.4 \\
\hline
\end{tabular}


1 Table 9 Estimation of the kinetic fractionation factor for $\mathrm{H}_{2}{ }^{18} 0$ by using Eq. (16). Calculated

2 values of the standard error as well as their minimum and maximum are also reported, based

3 on estimates of sampling errors (Appendix E). Values are given in per mil $\left(1-\alpha_{K}\right) * 1000$ and

$4 \sigma_{\alpha \mathrm{K}} * 1000$. Lines in grey correspond to the same dates but the soil water content and isotopic

5 ratio were sampled over different depths: $0-2.5 \mathrm{~cm}$ in the top panel and $0-0.5$ or $0-0.1 \mathrm{~cm}$ in the

6 bottom panel. For the last three lines figures in parenthesis provide the results when the soil

7 water content and liquid isotopic ratio were taken at the peak.

\begin{tabular}{lllll}
\hline Decimal Averaged & $\begin{array}{l}\text { Minimum } \\
\text { Day of } \alpha_{K}{ }^{18} \mathrm{O}\end{array}$ & $\alpha_{K}{ }^{18} \mathrm{O}$ & $\alpha_{K}{ }^{18} \mathrm{O}$ & $\begin{array}{l}\text { Standard } \\
\text { error } \alpha_{K}\end{array}$ \\
the Year & & & & ${ }^{18} \mathrm{O}$ \\
\hline
\end{tabular}

\begin{tabular}{|c|c|c|c|c|}
\hline \multicolumn{5}{|c|}{ Soil values are averaged over the $0-2.5 \mathrm{~cm}$ depth } \\
\hline 101.50 & 5.4 & -14.3 & 25.0 & 10.7 \\
\hline 132.46 & -6.3 & -29.3 & 16.8 & 11.7 \\
\hline 138.63 & -1.1 & -19.2 & 17.0 & 11.5 \\
\hline 145.41 & 0.4 & -16.8 & 17.6 & 11.8 \\
\hline 154.43 & -0.8 & -19.5 & 17.9 & 12.2 \\
\hline 164.58 & 1.6 & -14.7 & 17.9 & 10.8 \\
\hline 171.65 & -1.1 & -18.4 & 16.2 & 11.0 \\
\hline 181.58 & -7.6 & -33.4 & 18.3 & 12.6 \\
\hline 192.53 & -13.7 & -50.6 & 23.3 & 16.8 \\
\hline 220.74 & 6.8 & -5.3 & 19.0 & 6.4 \\
\hline 231.77 & 6.4 & -5.4 & 18.1 & 6.3 \\
\hline 252.42 & 8.8 & -1.1 & 18.7 & 5.1 \\
\hline 264.55 & 6.9 & -3.0 & 16.8 & 5.2 \\
\hline 287.65 & 5.1 & -2.0 & 12.3 & 4.1 \\
\hline 336.58 & 10.6 & 3.5 & 17.6 & 3.5 \\
\hline 439.58 & 6.1 & -1.4 & 13.6 & 3.8 \\
\hline
\end{tabular}

Soil values are averaged over the $0-0.5$ or $0-1$ cm depth

\begin{tabular}{llllll}
132.46 & 0.0 & -15.4 & 15.3 & 10.6 \\
154.43 & 11.0 & -20.9 & 42.9 & 15.0 \\
192.53 & -6.1 & -32.3 & 20.1 & 13.2 \\
264.55 & $2.3(11.5)$ & $-5.9(-0.1)$ & $10.4(23.0)$ & $5.1(5.6)$ \\
336.58 & $5.3(17.8)$ & $-0.4(10.4)$ & $11.0(25.2)$ & $3.2(3.8)$ \\
439.58 & $4.8(18.9)$ & $-1.7(11.6)$ & $11.3(26.3)$ & $3.5(3.8)$ \\
\hline
\end{tabular}


1 Fig.1. Photo of the experimental set up.

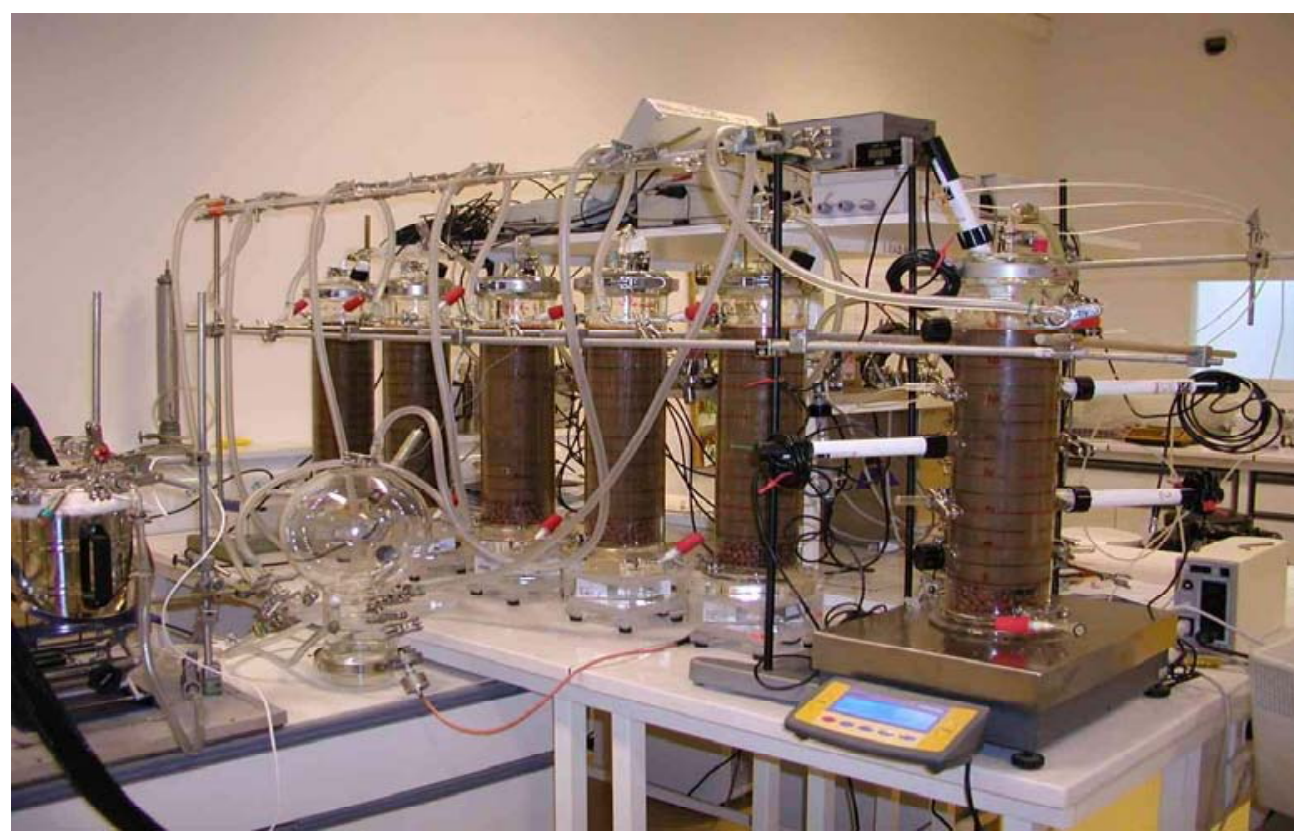

3 Fig. 2. Scheme of the experimental set up (view from the top).

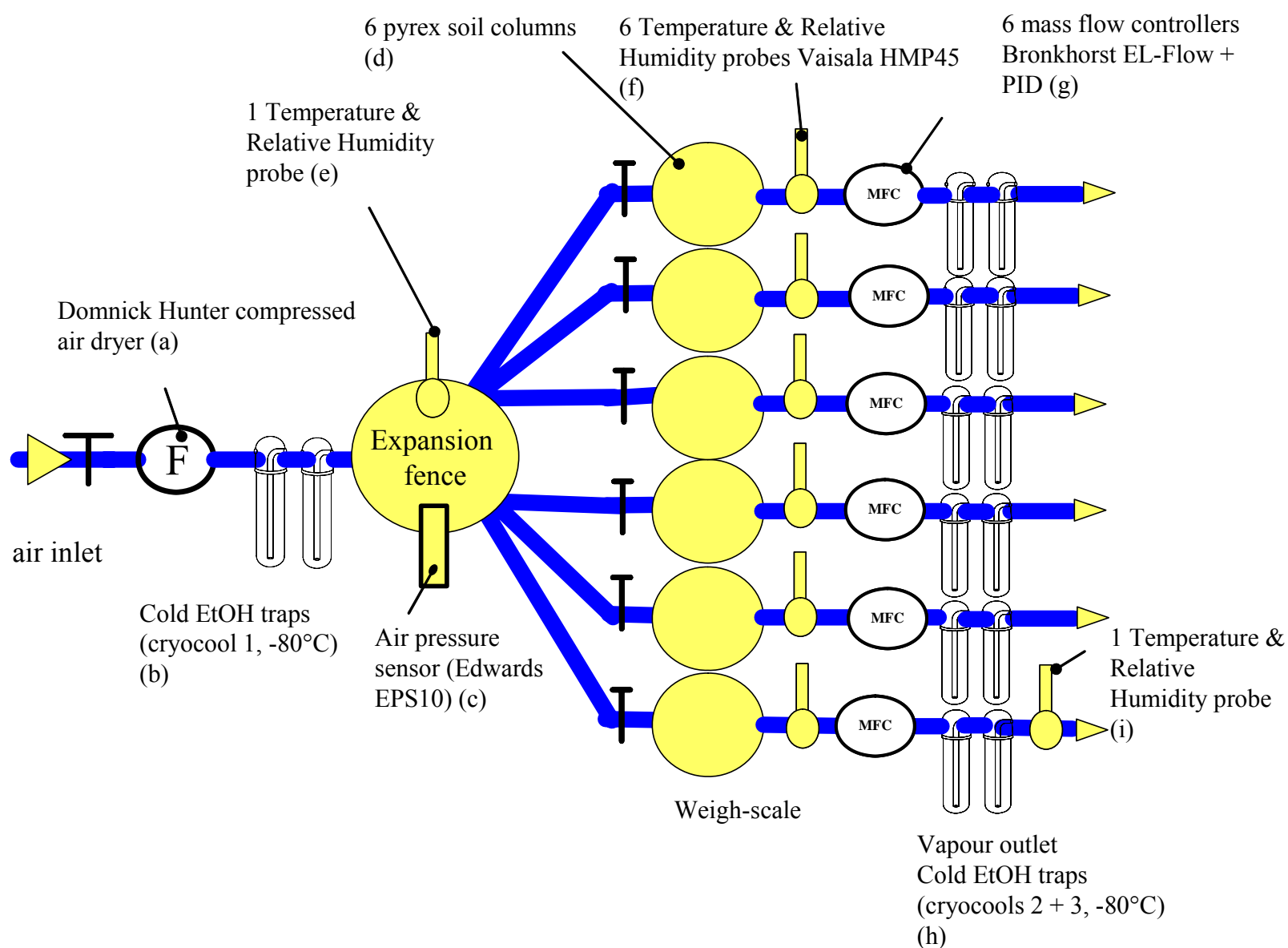


1 Fig. 3: Time evolution of air temperture and relative humidity at the outlet of column 1

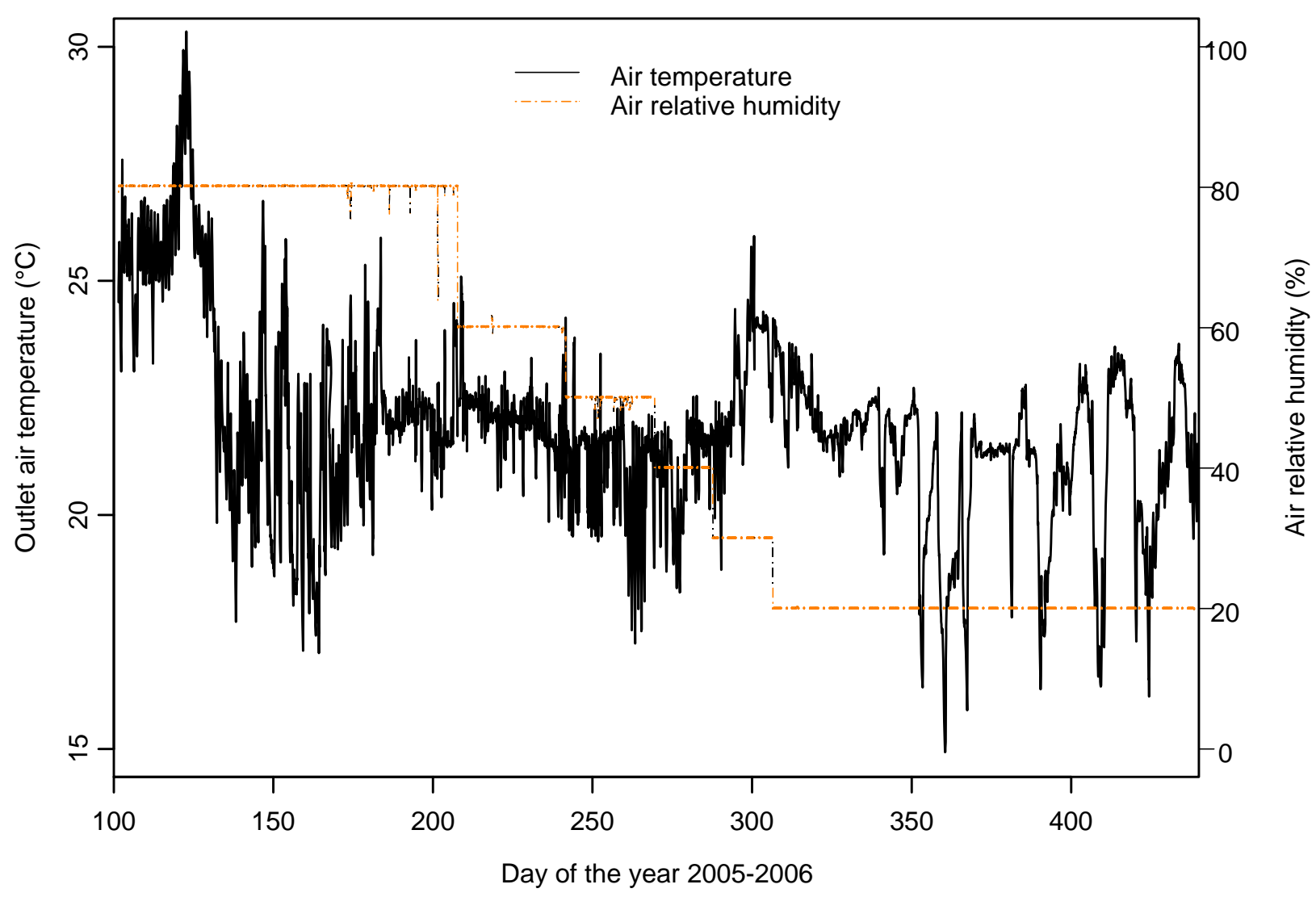


1 Figure 4. Evolution of the oxygen 18 composition of the liquid water as function of the

2 gravimetric water content $\left(\mathrm{kg} \mathrm{kg}^{-1}\right)$. The results were obtained after $15 \mathrm{~h}$ of distillation and

3 corrected for the efficiency of the extraction. The target initial oxygen 18 isotopic

4 composition of the liquid water is $-7.10 \pm 0.05 \%$. Vertical bars correspond to the analytical $5 \operatorname{errors}( \pm 0.1 \%)$.

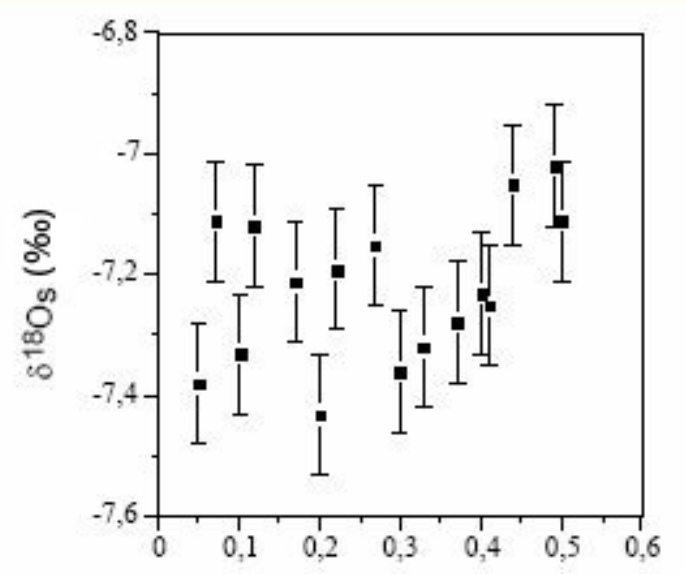


1 Figure 5. Retention curve $h(\theta)$ of the soil. The squares correspond to the measured $(h, \theta)$

2 couples at $-2.5 \mathrm{~cm}$ (full square), $-8 \mathrm{~cm}$ (crosses), $-16 \mathrm{~cm}$ (open triangles). The continuous line

3 corresponds to the fitted Van Genuchten model $\frac{\theta}{\theta_{\mathrm{sat}}}=\left(1+\left(\frac{h}{h_{\mathrm{VG}}}\right)^{n}\right)^{-m}$ with $m=1-\frac{2}{n}$ for

4 the $-2.5 \mathrm{~cm}$ data. Values of the parameters are $n=2.36, h_{V G}=-1.05 \mathrm{~m}, \theta_{\text {sat }}=0.444$.

5

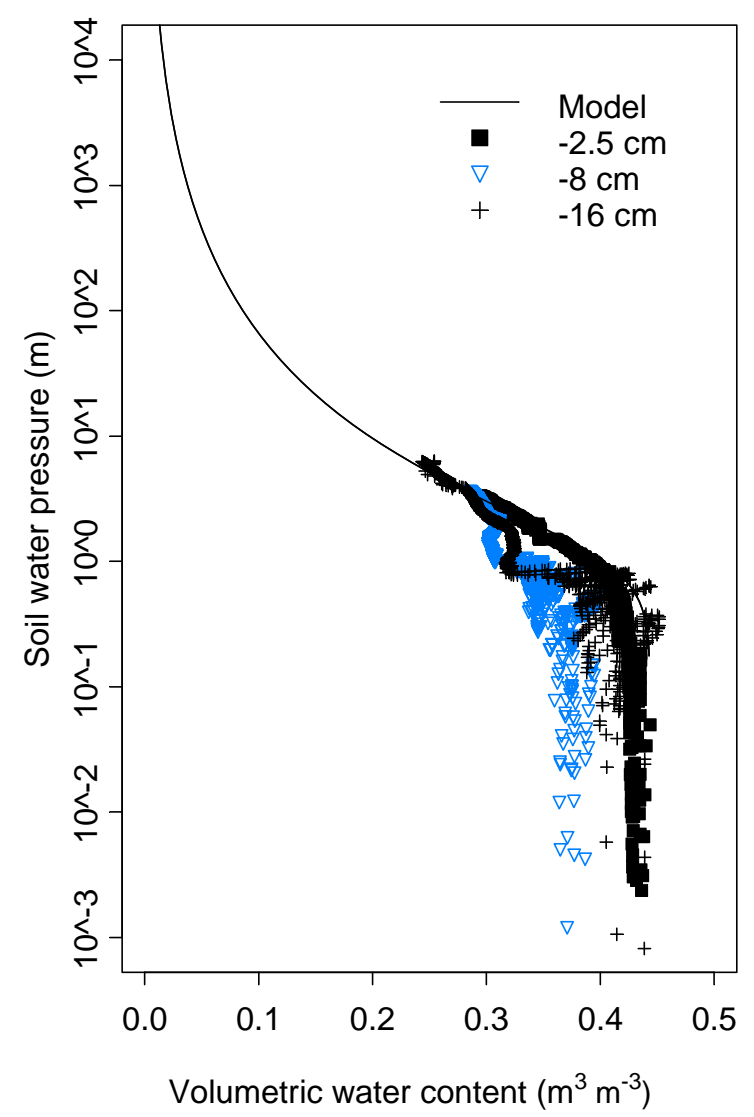

6 
1 Figure 6. Comparison of the cumulative evaporation (left) and the instantaneous flux (right)

2 estimated by using the measures of air flow and water vapor humidity at the outlet (full

3 black), the weighting of the columns (dashed black), the trapped water volume at the outlet

4 (dashed light) and the calculated soil water storage (full light) for column 1 (top) and column 54 (bottom).
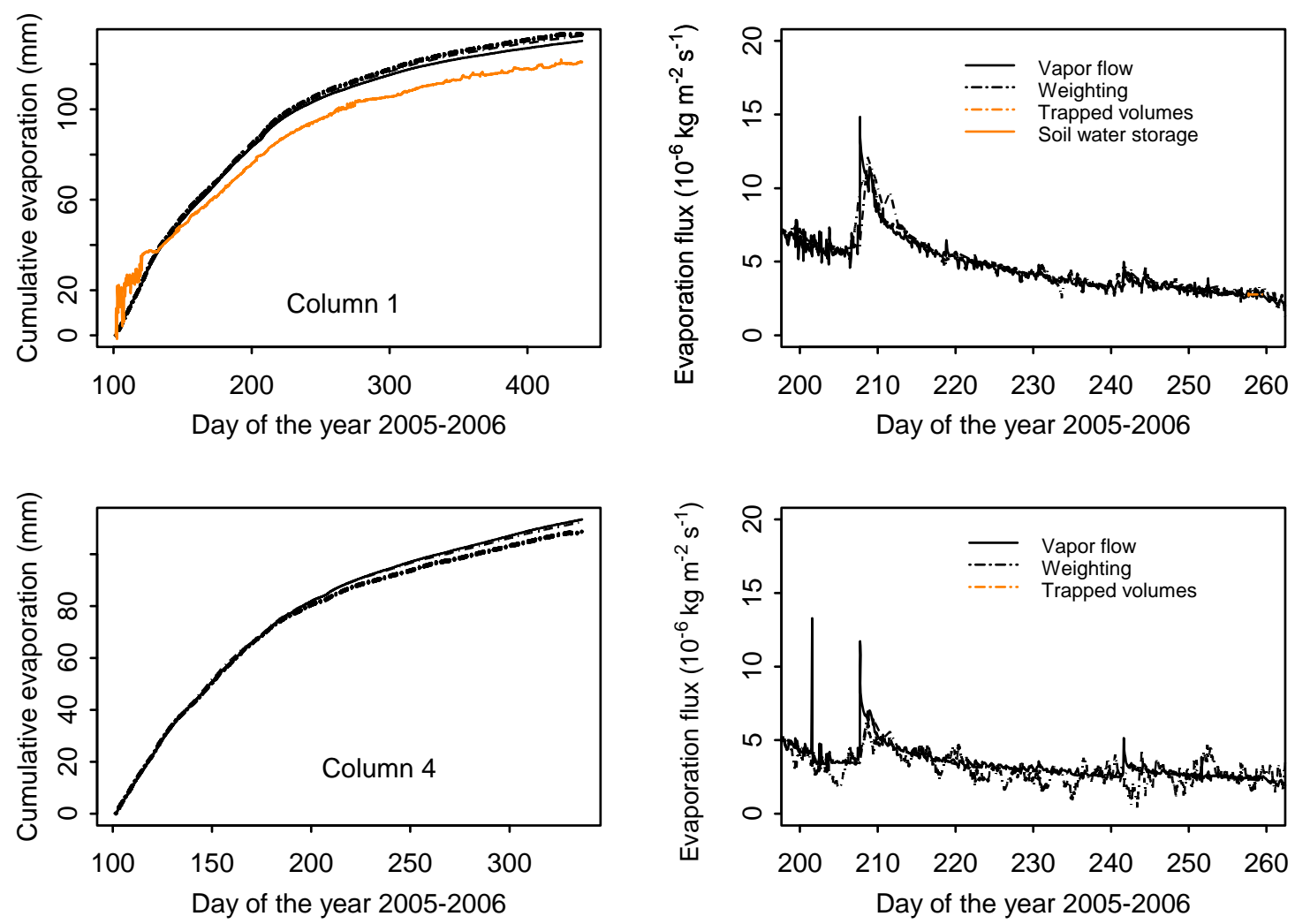
1 Figure 7. Evaporation flux (top) and cumulative evaporation (bottom) of the six columns.

2 Values were calculated using Method 1.

3
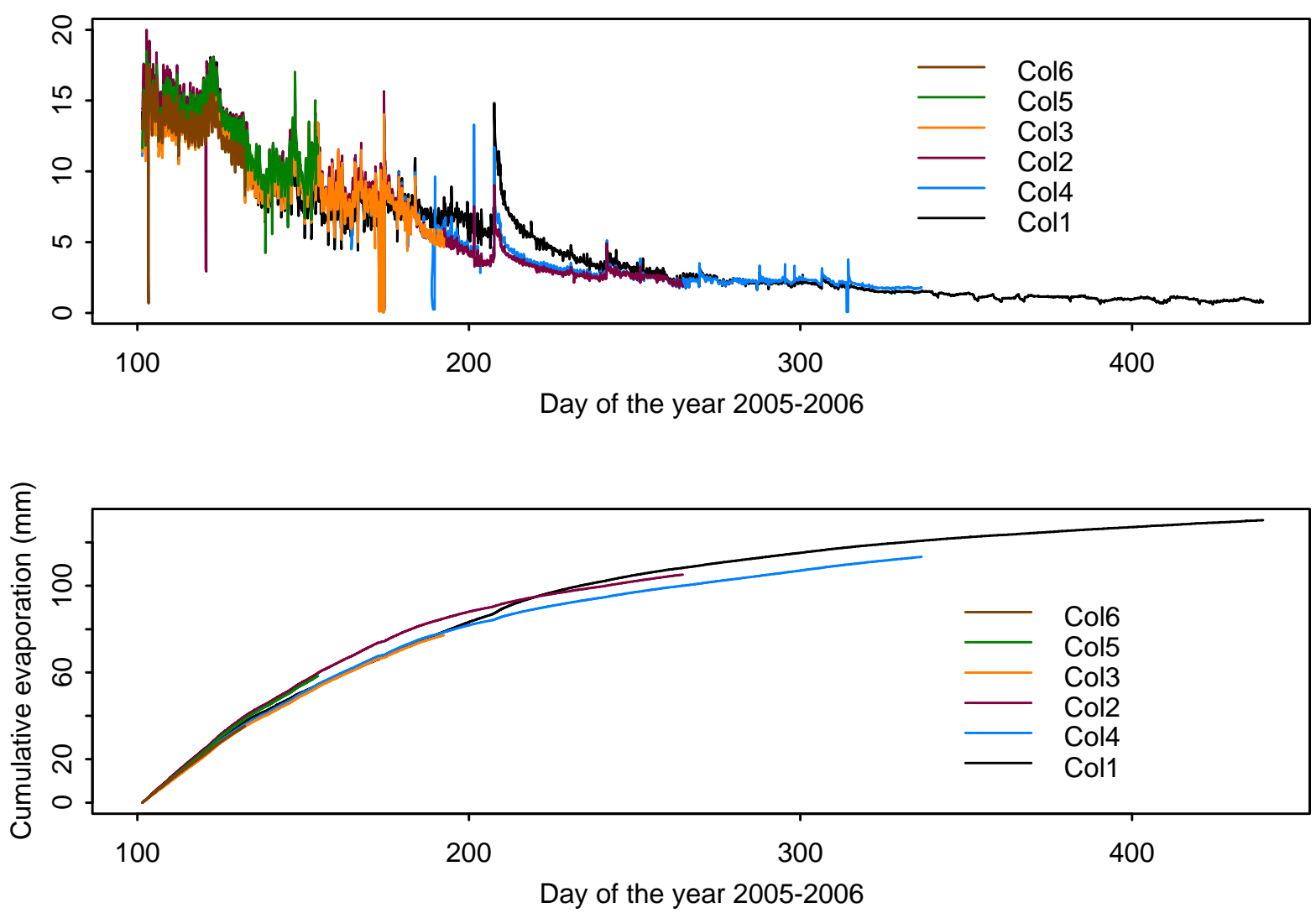

4 
1 Figure 8. Volumetric water content (left) and oxygen 18 isotopic ratio (right) (in $\%$ ) of the

2 six soil columns when they were dismantled. The vertical straight lines are the initial values.

3 DoY is Day of the Year

4
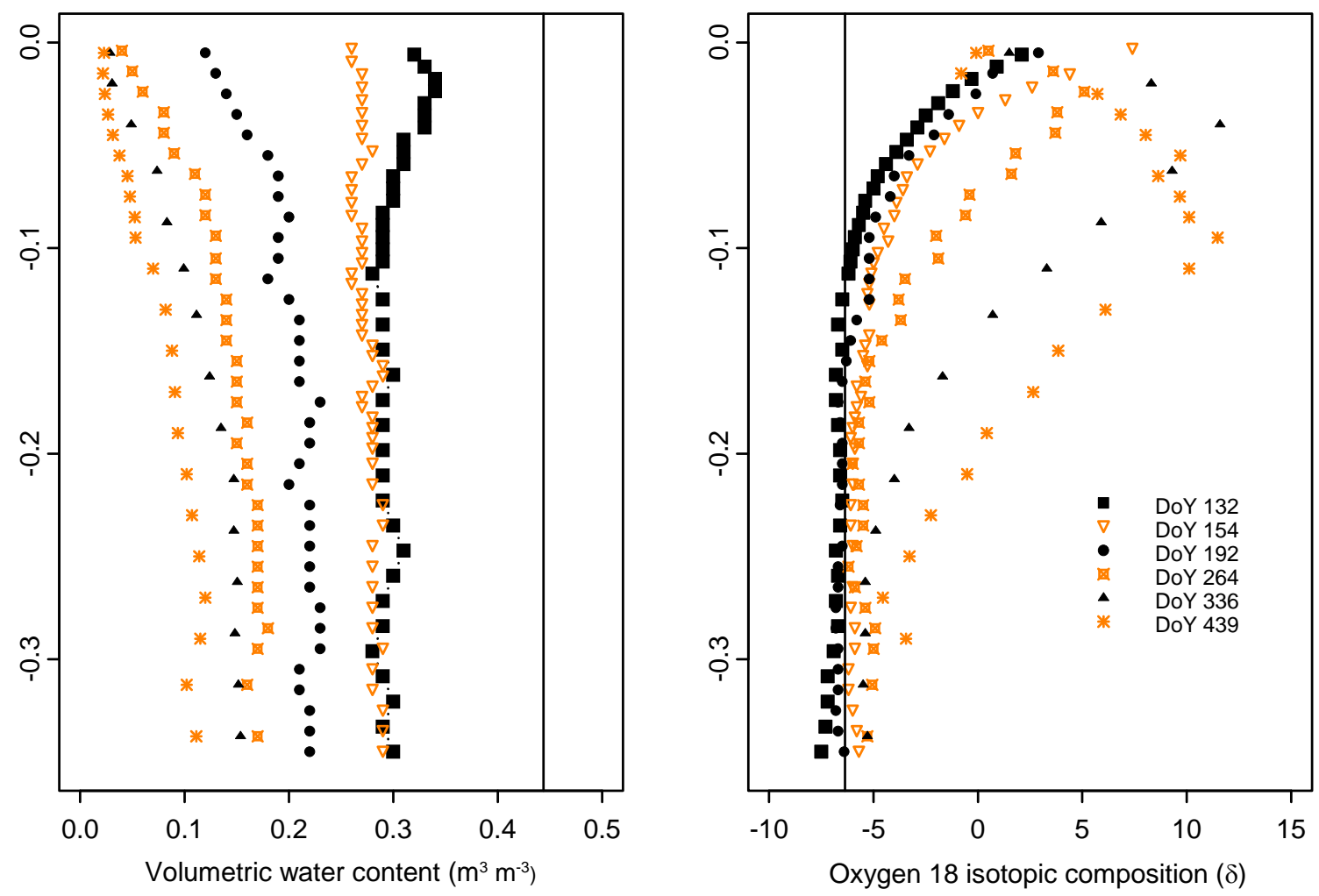
1 Figure 9. Time evolution of the oxygen 18 isotopic ratio of the evaporated water vapor for the

2 six columns. The horizontal black line gives the composition of the initial water $-6.4 \%$. The 3 sampling frequency is twice a day from DoY 101 to 136; once a day from DoY 137 to 224

4 and then about one sample every two or three days.

5

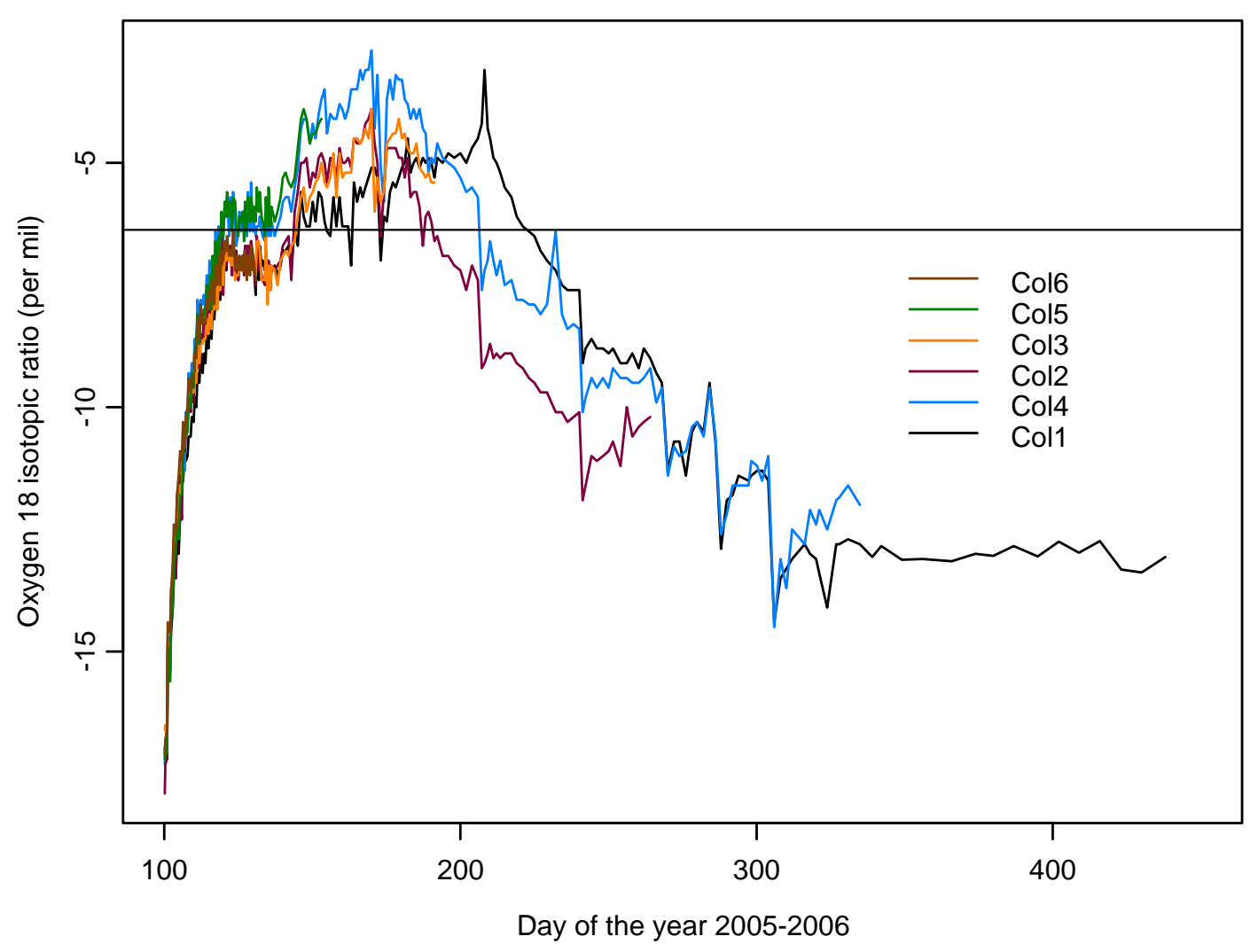

6 
1 Figure 10. Comparison of the measured oxygen 18 isotopic composition of the evaporated

2 water vapor (squares) and the calculated one using Eq. (6) with $\alpha_{K}=1.0189$ (points). Values

3 of the standard error, as well as their minimum and maximum, estimated using analytical and

4 sensor accuracy errors are also plotted. Results with soil water content and liquid isotopic

5 ratios sampled over the $0-2.5 \mathrm{~cm}$ and $0-0.5$ or $0-1 \mathrm{~cm}$ layers are represented in the top and

6 bottom panels, respectively.


7 
1 Figure 11. Comparison of the measured oxygen 18 isotopic composition of the evaporated

2 water vapor (squares) and the calculated one using Eq. (6) with $\alpha_{K}=1.0189$ (points). Values of

3 the standard error, as well as their minimum and maximum, estimated using sampling errors

4 are plotted. Results with soil water content and liquid isotopic ratios sampled over the 0-2.5

$5 \mathrm{~cm}$ and $0-0.5$ or $0-1 \mathrm{~cm}$ layers are represented in the top and bottom panels, respectively.

1 Figure 12. Contribution of the various sources of errors on the calculated isotopic composition

2 of the evaporated water vapor for oxygen 18 for the sampling errors and $\alpha_{K}=1.0189$. Top

3 panel: when error on $\alpha_{K}$ is not taken into account. Bottom panel: when error on $\alpha_{K}$ is taken

4 into account. The dates in abscissa correspond to the lines in Table 6 in the same order. In the

5 legend the labels refer to errors on soil temperature $T_{s}(\mathrm{Ts})$, isotopic composition of the soil

6 surface liquid water $\delta_{i s}^{l}$ (deltal), water vapor above the soil column $\delta_{i a}^{v}$ (deltair), air

7 temperature $T_{a}(\mathrm{Ta})$, air relative humidity $h_{a}(\mathrm{ha})$, soil water content $\theta$ (theta) and kinetic

8 fractionation factor $\alpha_{K}$ (alphak).
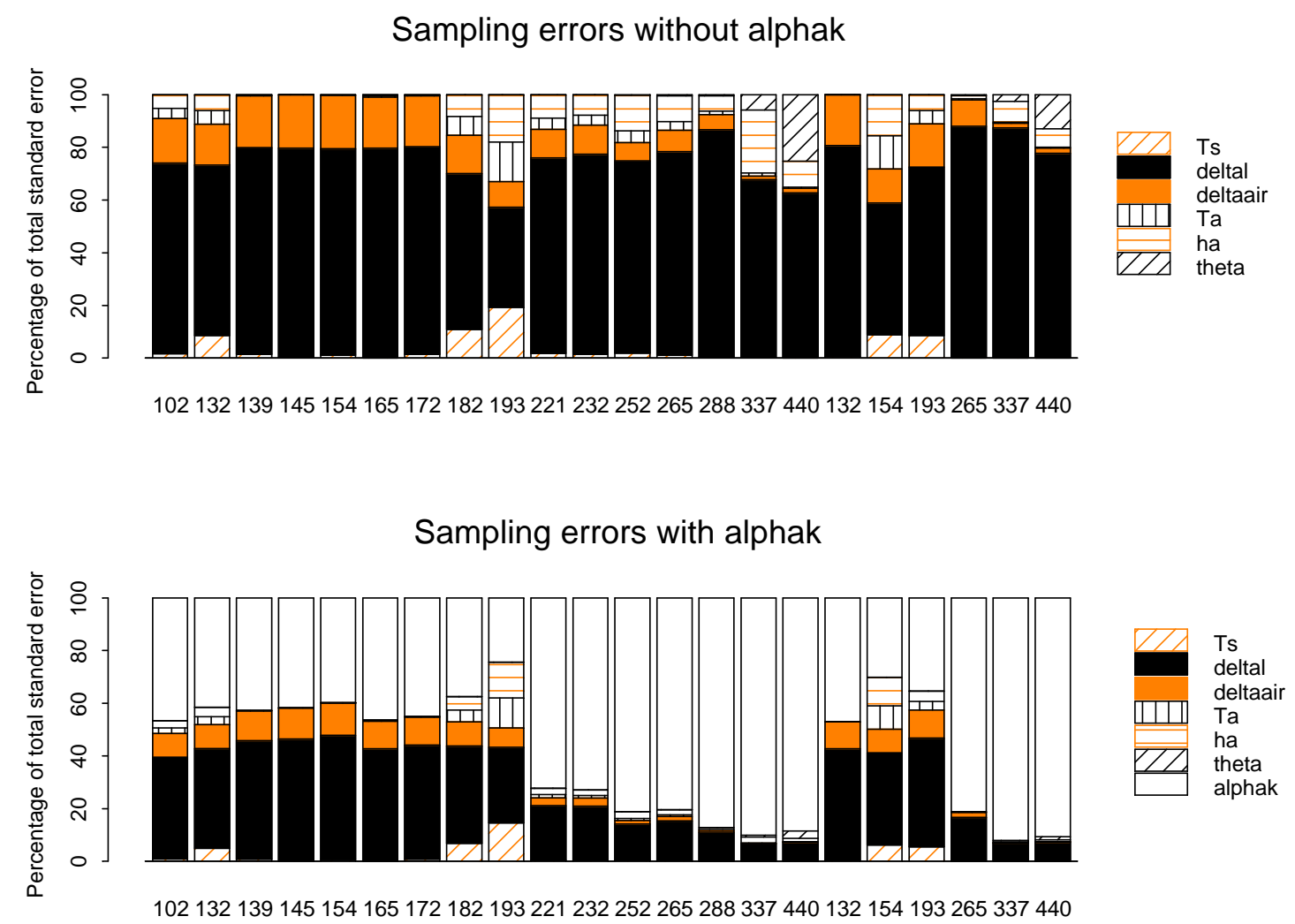
1 Figure 13. Value of the isotopic composition of the soil liquid water, required so that the 2 isotopic composition of the evaporated water vapor calculated using Eq. (6) matches the 3 measured value. The standard error, minimum and maximum values estimated using sampling 4 errors are also plotted. Measured values correspond to the $0-2.5 \mathrm{~cm}$ depth layer.

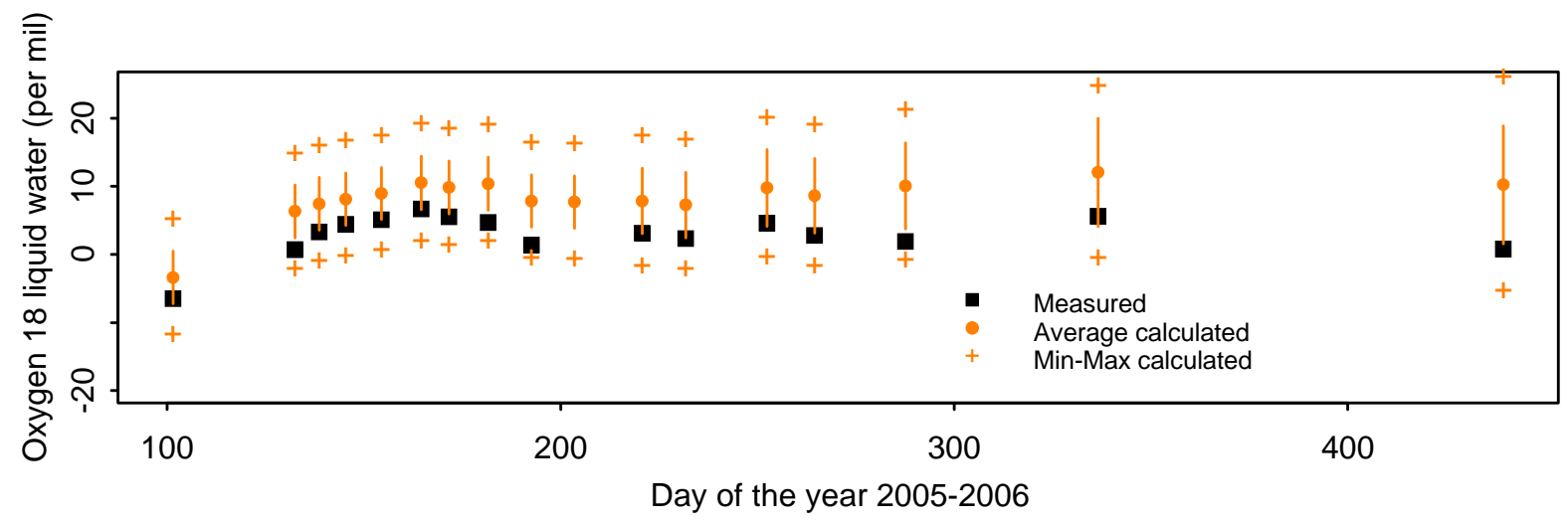


1 Figure 14 Contribution of the various sources of errors on the calculated isotopic composition

2 of the soil liquid water required so that the isotopic composition of the evaporated water

3 vapor calculated using Eq. (6) matches the measured value calculated using oxygen 18 and

4 the sampling errors. Top: error on the kinetic fractionation factor is not considered. Bottom:

5 Error on the kinetic fractionation factor is considered. The dates in abscissa correspond to the

6 lines in Table 8 in the same order. In the legend the labels refer to errors on soil temperature

$7 \quad T_{s}(\mathrm{Ts})$, water vapor above the soil column $\delta_{i a}^{v}$ (deltair), air temperature $T_{a}(\mathrm{Ta})$, air relative

8 humidity $h_{a}\left(\right.$ ha), soil water content $\theta$ (theta) and kinetic fractionation factor $\alpha_{K}$ (alphak).
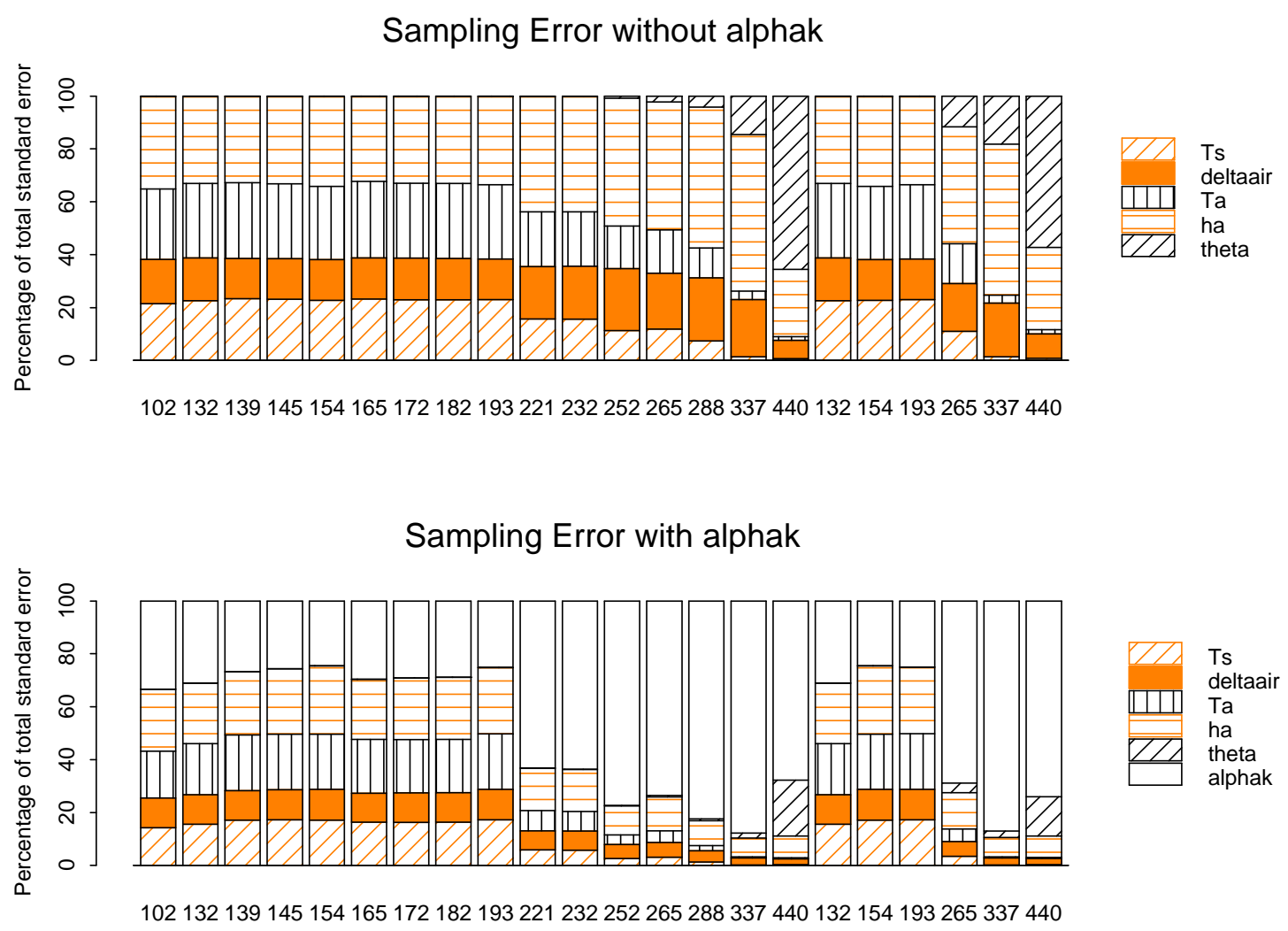
1 Figure 15. Contribution of the various sources of errors on the calculated kinetic fractionation

2 factor for oxygen 18 and for the sampling errors. The dates in abscissa correspond to the lines

3 in Table 9 in the same order. In the legend the labels refer to errors on soil temperature $T_{s}$

4 (Ts), isotopic composition of the soil surface liquid water $\delta_{i s}^{l}$ (deltal), water vapor above the

5 soil column $\delta_{i a}^{v}$ (deltair), air temperature $T_{a}(\mathrm{Ta})$, air relative humidity $h_{a}($ ha), soil water

6 content $\theta$ (theta).

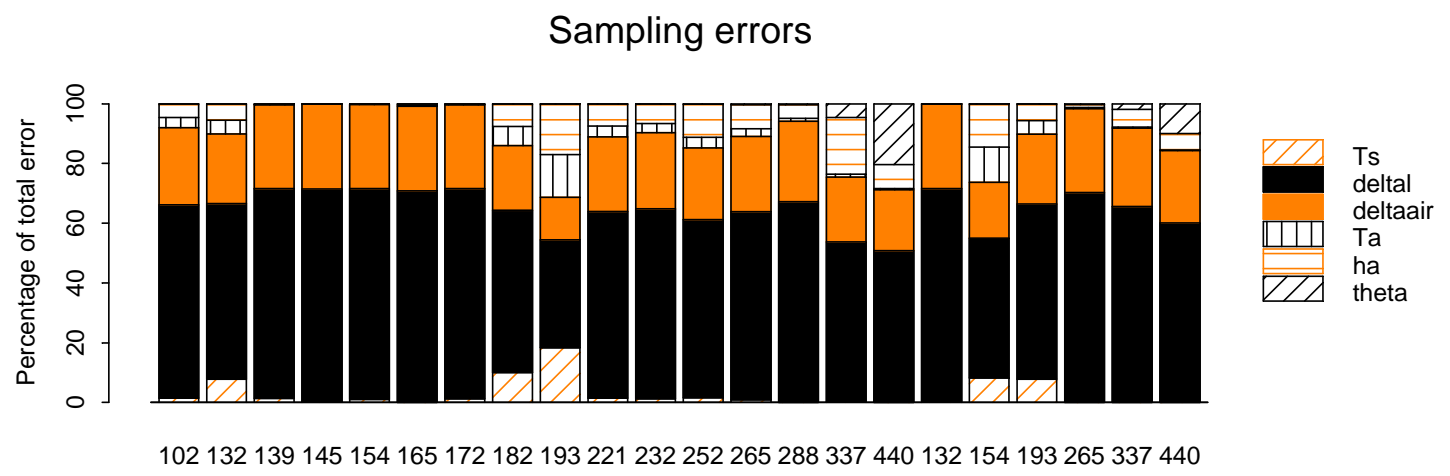

